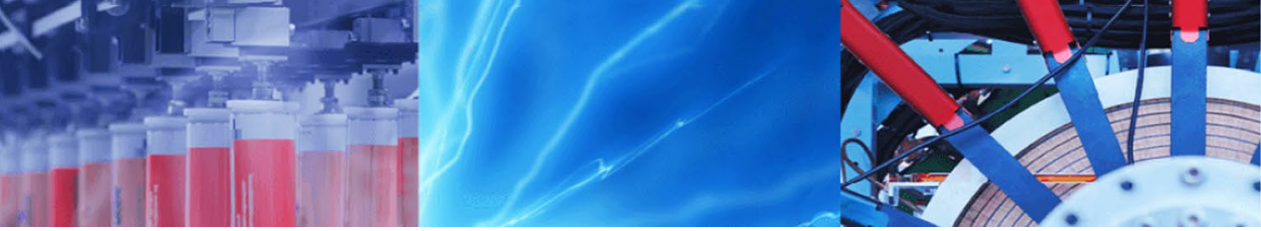

Research Article

\title{
3-Dimensional numerical study of wave-induced seabed response around three different types of wind turbine pile foundations
}

\author{
Richard Asumadu $^{1,2,3}$ (D) Jisheng Zhang ${ }^{1,2} \cdot$ H. Y. Zhao ${ }^{1,2} \cdot$ Hubert Osei-Wusuansa $^{3} \cdot$ Alex Baffour Akoto $^{1}$
}

(c) Springer Nature Switzerland AG 2019

\begin{abstract}
In this paper, preliminary study is conducted on oscillatory wave-induced seabed response around three configuration cases of pile support foundations applying a 3-dimensional integrated numerical model to study and comparatively analyzed them. In the past, numerous studies have been conducted into exploring the wave-seabed-structure interaction (WSSI) mostly around monopile. However, attention on other pile support structure foundations is minimal. In this present study, Reynolds-Average Navier-Stokes equations with $k$-turbulence closure as well as Biot's poroelastic theory are employed to govern the wave motion and porous seabed foundation respectively. The present numerical model is compared with available physical experimental data to determine its capability of simulating the WSSI around pile structures. Results analysis indicate that the impact of wave forces and wave pressure on the gravity-based support foundation is relatively higher than that of the monopile and tripod support pile due to the large peripheral area it occupied. Result of the momentary wave-induced liquefaction depth for the three configuration cases of pile structures at the upstream side in the seabed foundation shows that the tripod support pile has higher tendency resistance against wave-induced liquefaction, which may perhaps be due to the additional legs.
\end{abstract}

Keywords 3-Dimensional · Wave-induced seabed response · Gravity-based pile · Monopile · Tripod support pile

\section{Introduction}

In $2009,81 \%$ of the global energy production source was made up of fossil fuel. According to the synthesis report from the International Panel on Climate Change (IPCC) [1], the burning of fossil fuels has resulted in the warmest temperature conditions in last 35 years period between 1983 and 2018, which globally has significantly impacted on climatic conditions. Further, the report recommends that a greater portion of energy should be derived from a renewable low carbon source by 2050 to completely phase out fossil fuel by 2100 . The ocean covers close to $71 \%$ of the earth surface and one of the largest reservoir of low carbon renewable energy. Ocean renewable energy can be utilized in five forms, which include tide, underwater current, temperature differences, ocean surface wave and wind conditions [2]. It worth noting, extracting energy from these sources requires deep-water construction.

In the past two decades, there has been intensive development of offshore engineering around the globe in search of alternative power source, most especially offshore wind turbines $[3,4]$. However, the immense marine constructions have attracted interest from coastal engineers, geotechnical experts, and scientific researchers in the discipline of offshore engineering to examine the WSSI phenomenon. One fundamental reason for the upward interest is that these offshore installations have been damaged by the wave-induced dynamic seabed response in the surrounding structure, rather than from construction causes [5-7]. An example is the reported case by $[8,9]$ on

\footnotetext{
$\triangle$ Richard Asumadu, asumadur@yahoo.com; $\varangle$ Jisheng Zhang, jszhang@hhu.edu.cn | ${ }^{1}$ Key Laboratory of Coastal Disaster and Defence (Hohai University) Ministry of Education, Nanjing, China. ${ }^{2}$ College of Harbor, Coastal and Offshore Engineering, Hohai University, Nanjing 210098, China. ${ }^{3}$ Hydrological Services Department, Division for Coastal Engineering, MB 501, Accra, Ghana.
}

SN Applied Sciences (2019) 1:1401 | https://doi.org/10.1007/s42452-019-1484-2 
the failure of the pile foundation which was due to waveinduced soil movement of the south pass " 70 " oil platform in Mississippi.

To date, different types of offshore wind turbine foundations (or support structures) have been constructed and this could be observed by their underwater configuration as shown by Miceh [10] in Fig. 1. The monopile is the most often used foundation in the wind farm turbines in offshore regions due to their easy deployment in shallow to medium ocean water depth. The monopile structure foundation is well adapted to site with water depth ranging from 0 to $30 \mathrm{~m}$. The gravity-based support structure foundation is a simple type foundation with larger coning diameter base. The gravity-based support pile relies on the coning base for support as the name implies, vertical pressure from the structure is imposed to the vicinity below the substructure stand, and also the seabed supports the structure and resists it from overturning. The gravity-based foundation is well suited for soil with homogeneous characteristics. They are mostly used in shallow water depth ranging between 0 and $20 \mathrm{~m}$. The gravity-based support structure foundation is usually considered expensive to construct in comparison with other support pile structure foundation. The tripod pile support structure foundation is considered to be hybrid of the monopile foundation and the three-legged lattice/jacket pile structure foundation. This type of pile structure foundation is well suited for deeper waters, the pile is mostly driven from 10 to $35 \mathrm{~m}$ into the seabed foundation. The main advantages of the tripod support structure foundation are that, they are applicable to all type of soil and also minimum ground preparation is required at the site before installation. The tripod support pile has the capability to resist scouring and liquefaction.

Numerous studies in the past have been carried out either to investigate the scour development [11-13] or the wave force impacting on these types of pile support and the superstructure [14]. However, not much consideration has been given to the oscillatory wave-induced seabed response around these structures. In most recent time,
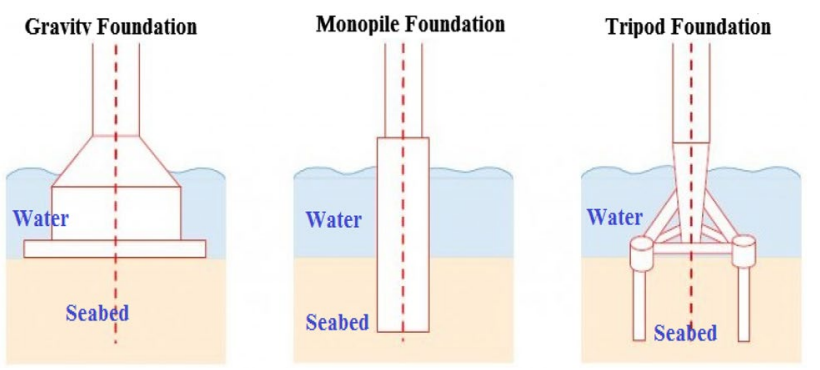

Fig. 1 Sketch of types of wind turbine foundations under the water observation the numerous investigation on 3-dimensional numerical studies on wave-induced response around pile structures has focused most of their attention around the monopile structure [15-21]. However, some few studies have carried out on gravity-based support structure [22-25].

Notwithstanding, most of these 3-dimensional studies on momentary wave-induced seabed response around pile structure foundations have followed the traditional manner of using the finite volume method (FVM) or the finite differential method (FDM) for the wave domain and the finite element method (FEM) for the solid domain (soil and structure) proposed by Ye et al. [26]. In which their study investigated a 3-dimensional one-way coupled model for the WSSI around the submerged breakwater. Lin et al. [20], employed the integrated FVM which integrates both the wave model and Biot's poro-elastic model to examine the oscillatory wave-induced seabed in the vicinity of the monopile foundation. However, the monopile foundation was understood to be inelastic and its response was not determined. Sui et al. [19] established a 3-dimensional integrated numerical model for the momentary wave-induced soil response around the monopile foundation. In their studies, the momentary wave-induced dynamic response of the porous seabed, structural dynamics of the monopile and their interaction were all determined. However, the interaction between the nonlinear wave and pile had a considerable impact on the porous seabed response. Zhao et al. [21] extensively carried out an investigation into a 3-dimensional integrated numerical model around a monopile foundation based on the RANS equations for the wave and Biot's consolidation equation for oscillatory seabed response as well as residual seabed response formulated by Sassa et al. [27]. Their results reveal that the analyses of seabed soil consolidation response in the presence of marine structure are essential for the liquefaction analysis. Most recently, $\mathrm{Li}$ et al. [22] employed an integrated numerical model to examine the oscillatory wave-induced seabed response and momentary wave-induced-liquefaction occurrence around offshore hexagonal gravity-based anisotropic soil foundation. The results from their studies investigated that the effect of anisotropic permeability for medium seabed sand should be considered when modeling. The aboveaforementioned studies were all concentrated towards an investigation into the monopile foundation structure or gravity-based support structure.

In this present study, comparative analyses are established to investigate the wave impact force, wave pressure and water elevation around three different types of pile structure foundations. Studies are also carried out on the pore pressure distribution and the momentary wave-induced liquefaction for the three different types of pile support structures. The RANS equations and the $k-\varepsilon$ 
turbulence closure model are employed to characterize the wave-induced fluid motion, whereas the Biot's poroelastic theory is adopted to capture the seabed response.

\section{Theoretical model}

In this section, the governing equations and the boundary conditions used to establish the 3-dimensional integrated wave and seabed computational sub-models are presented. The wave sub-model is based on the FDM solved equation in Flow 3D framework, while the COMSOL Multiphysics [28] software was used to establish the seabed sub-model, which the FEM solved-equation is assigned as the governing equation. Numerous studies in the past have employed these set of equations in the investigation of the WSSI around offshore pipelines $[29,30]$ breakwater structures $[31,32]$ and offshore pile structures $[20,21]$.

\subsection{Governing equation}

\subsubsection{Wave sub-model}

The wave motion around the inelastic pile structure is determined by applying the RANS equations by Hsu and Liu [33]. Equations (1) and (2) are used to solve the fluid motion while the $k-\varepsilon$ turbulence closure model in Eqs. (3) and (4) are applied on the turbulence effect in the flow medium. The RANS equations and $k-\varepsilon$ turbulence equations are expressed as follows:

RANS equations

$\frac{\partial u_{z i}}{\partial x_{i}}=0$

$\frac{\partial u_{z i}}{\partial \mathrm{t}}+u_{z j} \frac{\partial u_{z i}}{\partial x_{j}}=-\frac{1}{\rho_{z}} \frac{\partial P_{s}}{\partial x_{i}}+g_{i}+\frac{\partial \tau_{z i j}}{\partial x_{j}}$

with $u_{z i}=$ [the flow velocity]; $x_{i}, x_{j}=$ [the Cartesian coordinate for the 3-dimensioanl flow]; $\rho_{z}=$ [density of fluid] $; P_{s}=$ [pore water pressure]; and $g_{i}=$ [gravitational force $=9.81 \mathrm{~m} / \mathrm{s}$ ]. The turbulence effect of $k-\varepsilon$ closure model is obtained according to Rodi [34] and is denoted as;

$k-\varepsilon$ closure model

$\frac{\partial k}{\partial \mathrm{t}}+u_{z j} \frac{\partial k}{\partial x_{j}}=\frac{\partial}{\partial x_{j}}\left[\left(\frac{v_{t}}{\sigma_{k}}+v\right) \frac{\partial k}{\partial x_{j}}\right]+2 v_{t} \sigma_{z i j} \frac{\partial u_{z i}}{\partial x_{j}}-\varepsilon$

$\frac{\partial \varepsilon}{\partial \mathrm{t}}+u_{z j} \frac{\partial \varepsilon}{\partial x_{j}}=\frac{\partial}{\partial x_{j}}\left[\left(\frac{v_{t}}{\sigma_{\varepsilon}}+v\right) \frac{\partial \varepsilon}{\partial x_{j}}\right]+c_{1 \varepsilon} \frac{\varepsilon}{k}\left(2 v_{t} \sigma_{z i j}\right) \frac{\partial u_{z i}}{\partial x_{j}}-c_{2 \varepsilon} \frac{\varepsilon^{2}}{k}$ where $k=$ [turbulent kinetic energy]; $v=$ [kinematic viscosity frequency] and $\sigma_{z i j}=$ [fluid stress tensor defined as $\sigma_{z i j}=\frac{1}{2}\left(\partial u_{z i} / \partial x_{j}+\partial u_{z j} / \partial x_{i}\right)$ ]. From Rodi [34] the empirical coefficient $C_{1 \varepsilon} \approx 1.44, C_{2 \varepsilon} \approx 1.92, \sigma_{\varepsilon} \approx 1.3$, and $\sigma_{k} \approx 1.0$ respectively. For Eddy viscosity $\boldsymbol{v}_{\boldsymbol{t}}=C_{D}\left(\frac{k^{2}}{\varepsilon}\right)$, where $C_{D}$ is the constant Drag coefficient, relies on the strain rate as well as the gradient of velocity. The exchange relationship between the total stress $\tau_{z i j}$ in Eq. (2) and $k-\varepsilon$ is expressed as;

$\tau_{z i j}=2\left(v+c_{D} \frac{k^{2}}{\varepsilon}\right) \sigma_{z i j}-\frac{2}{3} k \delta_{i j}$

where $\delta_{i j}$ is known as a Kronecker delta function.

\subsubsection{Seabed sub-model}

In this study, the seabed sub-model is characterized by homologous/uniform relative sand particle properties with permeability in all directions. Biot's poro-elastic theory [35] is assigned to describe the seabed sub-model foundation. The equation governing the force balance can be written according to Jeng [36];

$\frac{\partial \sigma_{\mathrm{x}}^{\prime}}{\partial \mathrm{x}}+\frac{\partial \tau_{\mathrm{xy}}}{\partial \mathrm{y}}+\frac{\partial \tau_{\mathrm{xz}}}{\partial \mathrm{z}}=\frac{\partial p_{s}}{\partial \mathrm{x}}$

$\frac{\partial \tau_{\mathrm{xy}}}{\partial \mathrm{x}}+\frac{\partial \sigma_{\mathrm{y}}^{\prime}}{\partial \mathrm{y}}+\frac{\partial \tau_{\mathrm{yz}}}{\partial z}=\frac{\partial p_{s}}{\partial \mathrm{y}}$

$\frac{\partial \tau_{\mathrm{xz}}}{\partial \mathrm{x}}+\frac{\partial \tau_{\mathrm{yz}}}{\partial \mathrm{y}}+\frac{\partial \sigma_{\mathrm{z}}^{\prime}}{\partial \mathrm{z}}=\frac{\partial p_{s}}{\partial \mathrm{z}}$

where $\sigma_{x^{\prime}}^{\prime} \sigma_{y^{\prime}}^{\prime} \sigma_{z}^{\prime}=$ [horizontal and vertical effective stresses in xyz-direction]; $p_{s}=$ [pore water pressure] and $\tau_{x y}, \tau_{y x^{\prime}} \tau_{y z^{\prime}}$ $\tau_{z y}, \tau_{z x^{\prime}} \tau_{x z}=$ [shear stresses].

Henceforth the conservation of mass equation can be denoted as:

$\nabla^{2} p_{s}-\frac{\gamma_{w} \mathrm{n}_{s} \beta_{\mathrm{s}}}{\mathrm{K}_{\mathrm{s}}} \frac{\partial p_{s}}{\partial \mathrm{t}}=\frac{\gamma_{\mathrm{w}}}{\mathrm{k}_{\mathrm{s}}} \frac{\partial \varepsilon_{s x}}{\partial \mathrm{t}}$

$\varepsilon_{s x}=\left(\frac{\partial \mathrm{u}_{\mathrm{sx}}}{\partial \mathrm{x}}+\frac{\partial \mathrm{v}_{\mathrm{sx}}}{\partial \mathrm{y}}+\frac{\partial \mathrm{w}_{\mathrm{sx}}}{\partial \mathrm{z}}\right)$

where $\nabla^{2}=\frac{\partial^{2}}{\partial x^{2}}+\frac{\partial^{2}}{\partial y^{2}}+\frac{\partial^{2}}{\partial z^{2}}=$ [Laplace operator]; $K_{s}=$ [seabed permeability]; $\gamma_{w}=$ [unit weight of pore water] $u_{s x}, v_{s x}, w_{s x}=$ [the horizontal and vertical soil displacements in xyz-direction]; $n_{s}=$ [soil porosity]; $\varepsilon_{s x}=$ [volumetric strain] and $\beta_{s x}=$ [compressibility of seabed pore water pressure, which is denoted as: 
$\beta_{\mathrm{sx}}=\frac{1}{\mathrm{~K}_{\mathrm{wx}}}+\frac{1-\mathrm{S}_{\mathrm{r}}}{\mathrm{P}_{\mathrm{w}}}$

with $P_{w}=$ [absolute static water pressure]; $S_{r}=$ [degree of saturation]; and $K_{w x}=$ [elasticity modulus of fluid, which is taken as $2 * 10^{9} \mathrm{~N} / \mathrm{m}^{2}$ according to Yamamoto et al. [37]. The relationship of stress-strain for the force equilibrium in the soil are denoted as:

$\mathrm{G}_{s \mathrm{x}} \nabla^{2} u_{s x}+\frac{\mathrm{G}_{\mathrm{sx}}}{1-2 \mu_{\mathrm{s}}} \frac{\partial}{\partial \mathrm{x}} \varepsilon_{s x}=\frac{\partial p_{s}}{\partial \mathrm{x}}$

$\mathrm{G}_{\mathrm{sx}} \nabla^{2} v_{s x}+\frac{\mathrm{G}_{s x}}{1-2 \mu_{\mathrm{s}}} \frac{\partial}{\partial \mathrm{y}} \varepsilon_{s x}=\frac{\partial p_{s}}{\partial \mathrm{y}}$

$\mathrm{G}_{\mathrm{sx}} \nabla^{2} w_{s x}+\frac{\mathrm{G}_{\mathrm{sx}}}{1-2 \mu_{\mathrm{s}}} \frac{\partial}{\partial \mathrm{z}} \varepsilon_{s x}=\frac{\partial p_{s}}{\partial \mathrm{z}}$

with $G_{s x}=$ [shear modulus of soil $]$ and $\mu_{s}=$ [Poisson's ratio].

In the present study, the poro-elastic natural behavior of the seabed is applied to describe the sub-model. Hence the effective normal stresses and shear stresses can be expressed in terms of soil displacement as:

$\sigma_{\mathrm{x}}^{\prime}=2 \mathrm{G}_{\mathrm{sx}}\left[\frac{\partial \mathrm{u}_{\mathrm{sx}}}{\partial \mathrm{x}}+\frac{\mu_{\mathrm{s}}}{1-2 \mu_{\mathrm{s}}}\left(\frac{\partial \mathrm{u}_{\mathrm{sx}}}{\partial \mathrm{x}}+\frac{\partial \mathrm{v}_{\mathrm{sx}}}{\partial \mathrm{y}}+\frac{\partial \mathrm{w}_{\mathrm{sx}}}{\partial \mathrm{z}}\right)\right]$

$\sigma_{\mathrm{y}}^{\prime}=2 \mathrm{G}_{\mathrm{sx}}\left[\frac{\partial \mathrm{v}_{\mathrm{sx}}}{\partial \mathrm{y}}+\frac{\mu_{\mathrm{s}}}{1-2 \mu_{\mathrm{s}}}\left(\frac{\partial \mathrm{u}_{\mathrm{sx}}}{\partial \mathrm{x}}+\frac{\partial \mathrm{v}_{\mathrm{sx}}}{\partial \mathrm{y}}+\frac{\partial \mathrm{w}_{\mathrm{sx}}}{\partial \mathrm{z}}\right)\right]$

$\sigma_{\mathrm{z}}^{\prime}=2 \mathrm{G}_{s x}\left[\frac{\partial \mathrm{w}_{\mathrm{sx}}}{\partial \mathrm{z}}+\frac{\mu_{\mathrm{s}}}{1-2 \mu_{\mathrm{s}}}\left(\frac{\partial \mathrm{u}_{\mathrm{sx}}}{\partial \mathrm{x}}+\frac{\partial \mathrm{v}_{\mathrm{sx}}}{\partial \mathrm{y}}+\frac{\partial \mathrm{w}_{\mathrm{sx}}}{\partial \mathrm{z}}\right)\right]$

$\tau_{\mathrm{xz}}=G_{s x}\left[\frac{\partial \mathrm{u}_{\mathrm{sx}}}{\partial \mathrm{z}}+\frac{\partial \mathrm{w}_{\mathrm{sx}}}{\partial \mathrm{y}}\right]=\tau_{\mathrm{zx}}$

$\tau_{\mathrm{yz}}=G_{s x}\left[\frac{\partial \mathrm{v}_{\mathrm{sx}}}{\partial \mathrm{z}}+\frac{\partial \mathrm{w}_{\mathrm{sx}}}{\partial \mathrm{y}}\right]=\tau_{\mathrm{zy}}$

$\tau_{\mathrm{xy}}=G_{s x}\left[\frac{\partial \mathrm{u}_{\mathrm{sx}}}{\partial \mathrm{y}}+\frac{\partial \mathrm{v}_{\mathrm{sx}}}{\partial \mathrm{x}}\right]=\tau_{\mathrm{yx}}$

\subsection{Geometry}

In this paper, the solid support structures are developed in Solidworks, which is a Computer-Aided Design (CAD) software program for solid modeling. Figure 2a show is a tripod support structure created with a diameter thickness of $2.8 \mathrm{~m}$ and cylindrical height of $49 \mathrm{~m}$ for the main pile. The tripod consists of three foundation pile legs with a height of $23 \mathrm{~m}$ and a diameter of $1.0 \mathrm{~m}$, which act as axially loaded. Figure $2 \mathrm{~b}$ presents a monopile support structure with working platform conditions of diameter thickness of $2.8 \mathrm{~m}$ and cylindrical height of $49 \mathrm{~m}$ from apex to the base of the pile. Besides from the tripod and monopile support structures, Fig. 2c presents the gravity-based support pile with working platform conditions of diameter thickness of $2.8 \mathrm{~m}$ and $49 \mathrm{~m}$ for the cylindrical height from the cone base to the top. The base is shaped in the cone-like form with a radius of $10 \mathrm{~m}$, this serves as gravity support for the structure.

The computational domain comprises of constraint channel in which the pile foundation is placed. Figure 3 shows a snapshot of the whole computation domain with the pile structure established at the rock-bottom of the domain. The pile structure is positioned at a distance of $100 \mathrm{~m}$ behind the boundary of the flow inlet and at the center point of the two side walls. The total stretch of the computational domain is $400 \mathrm{~m}$ with a vertical and horizontal distance of the domain taken as $40 \mathrm{~m} \times 40 \mathrm{~m}$ respectively, to help mitigate reflection from the side walls.

\subsection{Mesh generation}

In this study, the fluid surface meshing is created with the volume mesh. In the pile foundation vicinity, the volume mesh is sub-divided into regular hexahedron cell. Figure 3 illustrates the volume mesh of the wave sub-model domain, which consists of a prism layer around the pile structure. The prism layer is at $90^{\circ}$ to the surface of the pile structure. Refine mesh are created around the surface of the structure in order to improve the exactness in the calculation. Table 1 shows the average size of each pile turbine structure in the wave fluid domain in which the total mesh number of the three configuration cases of the pile structures are listed.

In the case of the seabed sub-model, the surface is discretized using tetrahedral mesh elements, Fig. 4 shows the seabed sub-model with tetrahedral mesh elements which are automatically generated by the COMSOL Multiphysics [28] software. Around the area proximity to the pile structures, refine mesh is used to ensure computational accuracy. The minimum to maximum mesh element size used in the computation is $1.0 \mathrm{~m}-10 \mathrm{~m}$. A value of 1.4 is used for the maximum growth element, with 0.4 for the curvature factor and 0.7 for the resolution of narrow regions. Table 2 shows the mean size of each turbine pile foundation, which the total mesh number for the three cases of pile structures are listed.

\subsection{Numerical setup and boundary conditions}

Figure 5 depicts the cross-section of the 3 -dimensional wave and seabed sub-model of the WSSI around a pile structure foundation. The wave model shows the positions above the mud line surface and comprises of the wave and 

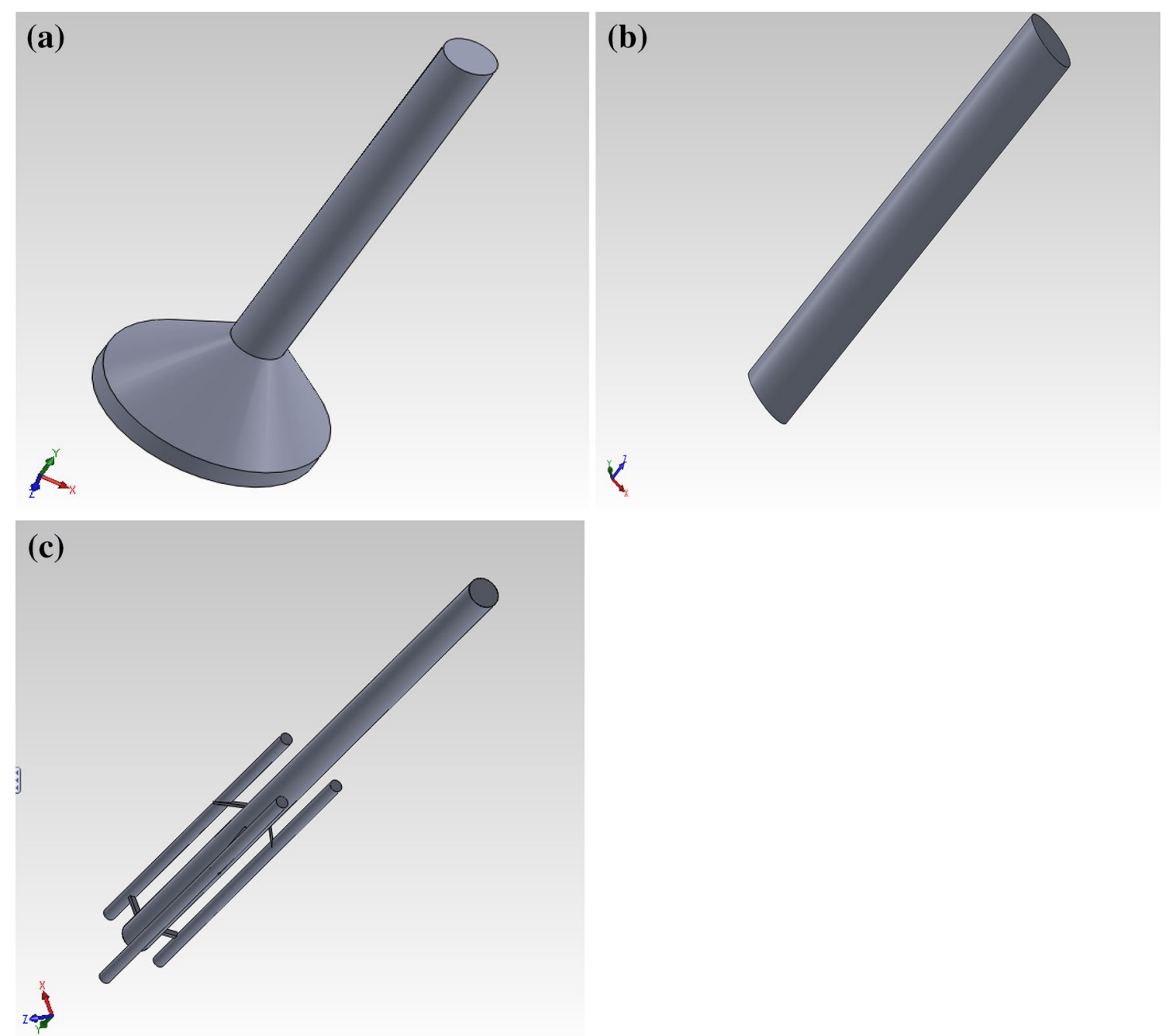

Fig. 2 Schematic diagrams of wind turbine foundations a gravity-based support pile, b monopile and $\mathbf{c}$ tripod support pile

Fig. 3 Snapshot of the mesh outline setup of the fluid domain and the pile foundation

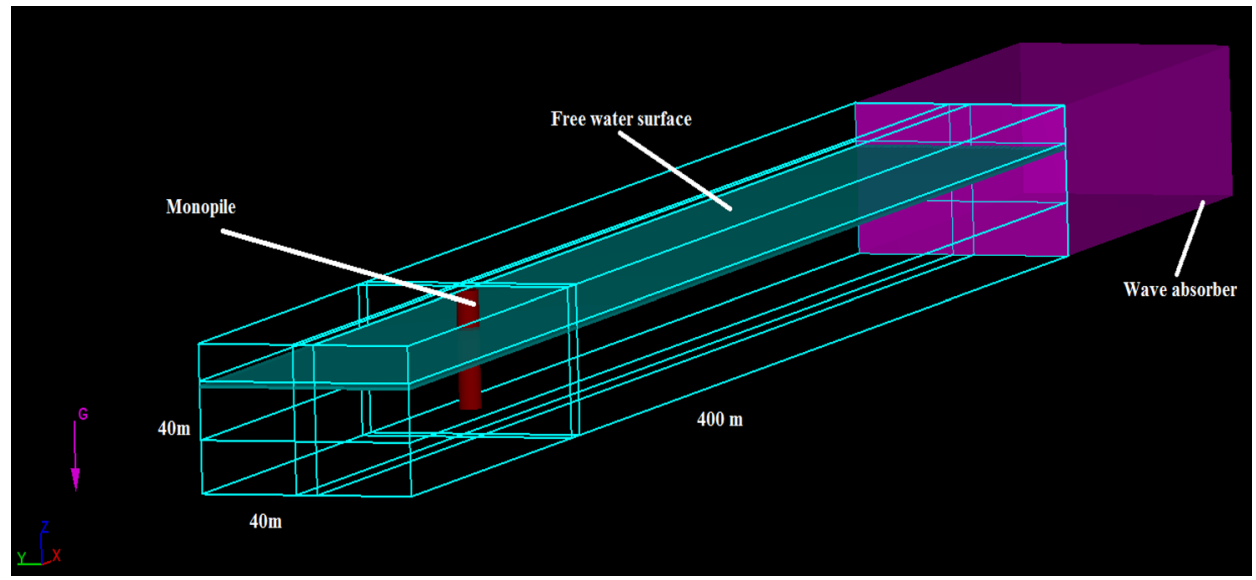

pile structure whereas the seabed sub-model indicates the position underneath the mud line. Which consists of the porous seabed and the embedded pile structure. However, in the case of the gravity-based support pile, the pile foundation is seated on the surface of the seabed foundation as shown in Fig. $4 \mathrm{c}$. The sectional plane size of the model 
Table 1 The mesh information for the fluid domain

\begin{tabular}{lllll}
\hline Foundation types & $x$ & $y$ & $z$ & Total mesh \\
\hline Monopile & 0.2 & 0.2 & 0.12 & $400,105,80$ \\
Gravity-based pile & 0.2 & 0.2 & 0.10 & $400,110,80$ \\
Tripod support pile & 0.2 & 0.2 & 0.12 & $400,105,80$ \\
\hline
\end{tabular}

computational is $\left(L+2 L_{s}\right) \times 2 B / 2$, where $L$ is the model seabed length, $L_{s}$ is the incident wavelength and $B$ is the model breadth. In Fig. 5 Cartesian coordinate " $O$ " is set as the wave inlet on the mud line surface for the integrated numerical model. The propagating wave direction for the computation domain is expressed by $\mathrm{x}-, \mathrm{y}$ - and, $\mathrm{z}$-axes. $\mathrm{D} \varnothing$ represents the diameter of the pile structure in the seabed, $D_{h}$ is the embedded depth of the pile structure, and $h$ is the thickness of the porous seabed.

To adequately solve the value problem for the boundary in the WSSI around the pile foundations. The following boundary conditions are firstly established

At the seabed-structure boundary, since the pile structure is inelastic and rigid, the normal gradient in relation to pore water pressure $\left(p_{s}\right)$ is considered zero.

$\frac{\partial p_{s}}{\partial n}=0$
At the plane surface between the soil and the structure, which is mostly known as a no-slip boundary, there is no relative displacement between the soils with respect to the pile structure.

$u_{s o}=u_{s t}$

where the subscript "so" = [soil] and "st"= [structure].

However, the total stress equilibrium conditions are specified as;

$\sigma_{s t}=\sigma_{s o}^{\prime} \quad \tau_{s t}=\tau_{\text {so }}$

The normal structure stress is imposed by the ocean waves at the wave-structure boundary, at the same time moment shear stress is considered to be negligible.

$\sigma_{s t}=-P_{w} \quad \tau_{s t}=0$

Table 2 The mesh information for the seabed foundation

\begin{tabular}{llll}
\hline Foundation types & $\begin{array}{l}\text { Domain ele- } \\
\text { ment size }\end{array}$ & $\begin{array}{l}\text { Boundary } \\
\text { element }\end{array}$ & Edge element \\
\hline Monopile & 18,005 & 2328 & 334 \\
Gravity-based pile & 20,809 & 3568 & 344 \\
Tripod support pile & 27,308 & 3020 & 634 \\
\hline
\end{tabular}

Fig. 4 Snapshot of mesh sizes of the integrated model for the three pile support foundations a monopile foundation $\mathbf{b}$ tripod support pile foundation c gravity-based support pile foundation (a)

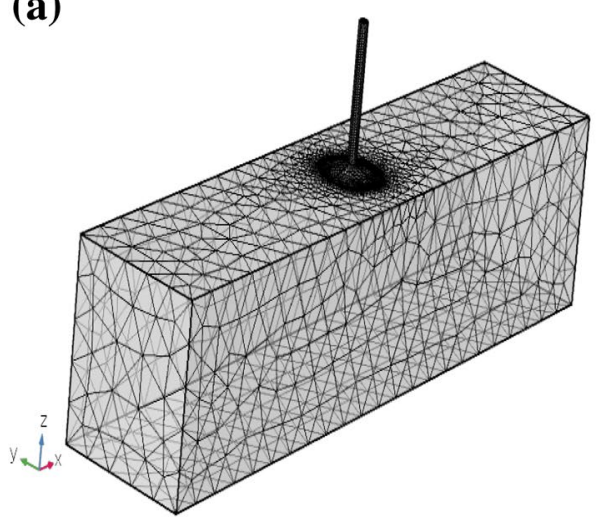

(b)

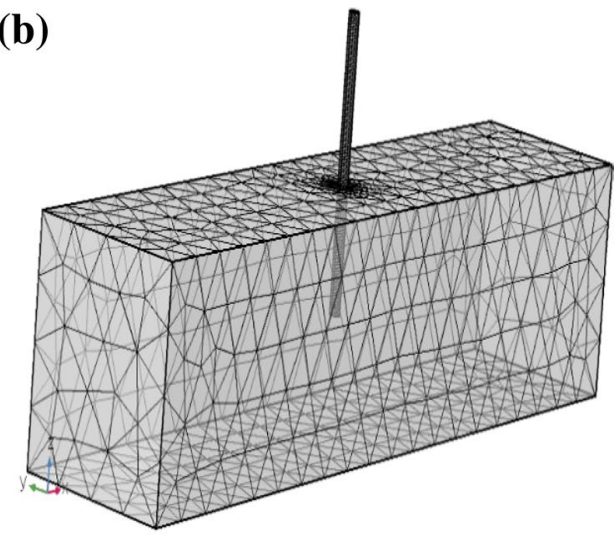

(c)

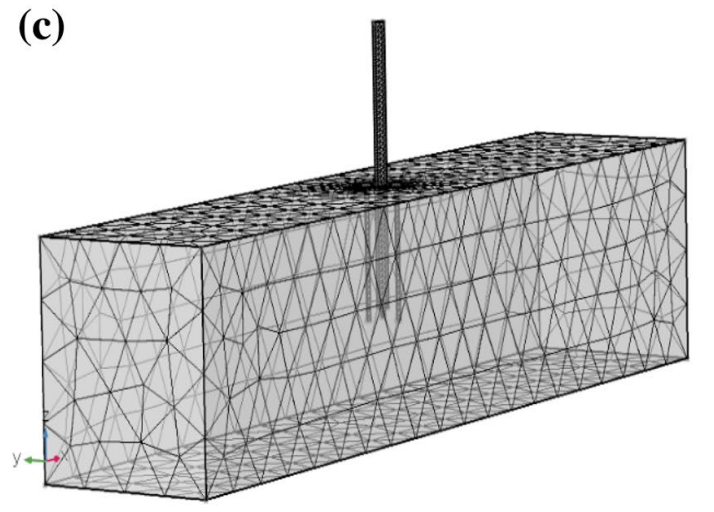


Fig. 5 Schematic diagram of wave-seabed-structure interaction of the pile structure. a Plan view $\mathbf{b}$ section view
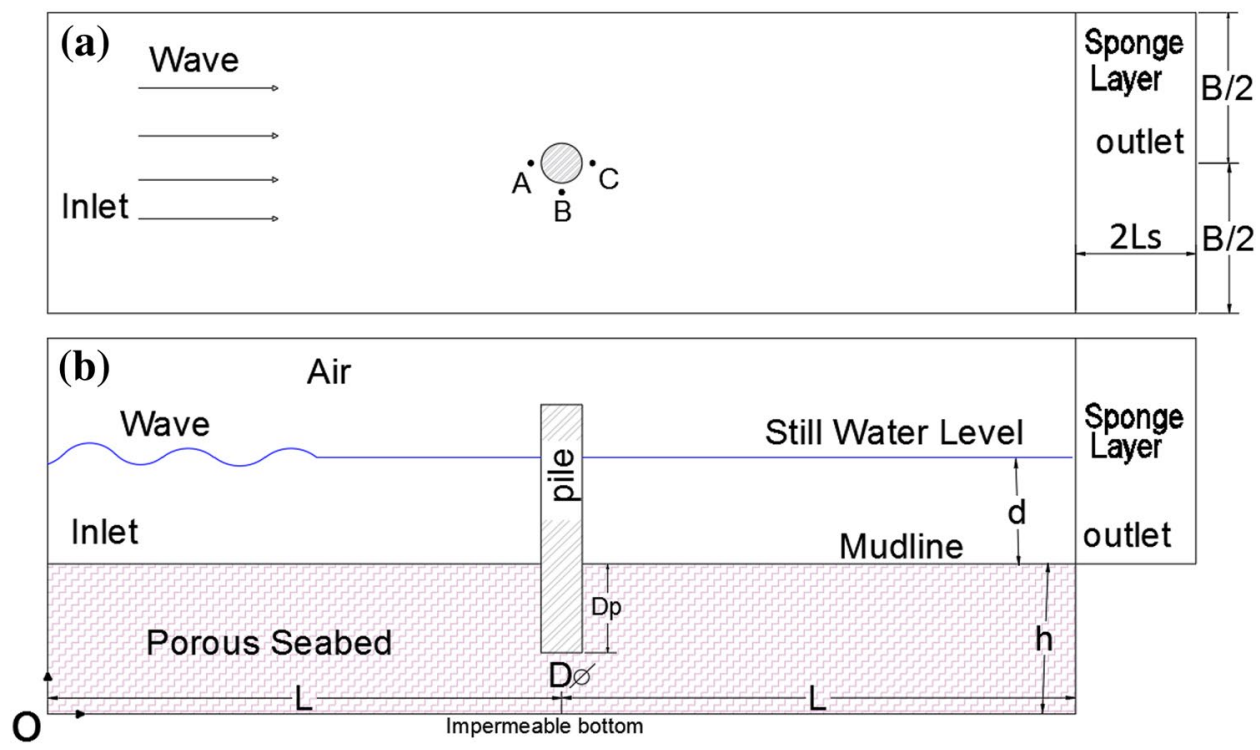

At the surface of the seabed, the vertical effective stress and shear stress of the soil disappears whereas the pore water pressure is equivalent to the wave-induced dynamic response.

$p_{s}=p_{w} \quad \sigma_{s o}^{\prime}=0 \quad \tau_{s o}=0$

At the underlying bottom and lateral boundary condition of the seabed foundation, the materials used at both sections are assumed to be impenetrable.

$u_{s}=v_{s}=w_{s}=\frac{\partial p_{s}}{\partial n}=0$ at $z=0$

At the outlet boundary of the fluid model, a sponge layer [38] is installed used to sponge up the wave reflection whereas at the inlet domain waves are generated from the wave-maker.

\subsection{Numerical scheme}

Sui et al. [39] pointed out that, a very small movement of the pile structure has little or no effect on the wave propagation. In this study, the proposed model comprises of both wave and seabed computational models. The wave motion is continuously solved using the FDM employed by the RANS equations. Thus at any period, the wave pressure is captured as dynamic wave loading thus to be applied on the seabed.

The wave and seabed computational sub-models are both integrated by applying the one-way coupling method. The captures dynamic wave loading from the wave motion is introduced into the seabed computational model as indicated in Eq. (25). Finally, the FEM in the COMSOL Multiphysics is employed to solve the Biot's poro-elastic equations in the seabed computational model

with the stated boundary conditions, hence the seabed response including oscillatory pore pressure is obtained.

\section{Model verification}

In this section, the wave computational model is verified against a physical experimental data conducted by Zang et al. [3] on a circular tube-shaped pile. Meanwhile, the seabed sub-model is verified against results from a physical experiment conducted by Huang et al. [40] at Hohai University Laboratory Center of College of Coastal, Harbor and Offshore Engineering, China.

\subsection{Verification with Zang et al. (2010)'s physical experiment on wave motion with monopile}

The present wave-sub-model is verified against a published laboratory physical experiment result from Zang et al. [3]. A number of experiments were carried out on a circular tube-shaped solid pile with diameter $D \varnothing=0.25 \mathrm{~m}$ in a wave flume with dimension $35 \mathrm{~m} \times 25 \mathrm{~m}$. The circular pile was set at $7.5 \mathrm{~m}$ farther away from the wave-maker. Table 3 indicates the input data parameter for the waveflume experiment on the cylindrical pile.

Table 3 Input data for verification case for wave-pile interaction Zang et al. [3]

\begin{tabular}{ll}
\hline Parameter & Values \\
\hline Wave height $(H)$ & $0.14 \mathrm{~m}$ \\
Wave period $(T)$ & $1.22 \mathrm{~s}$ \\
Water depth $(d)$ & $0.505 \mathrm{~m}$ \\
Diameter $(D \varnothing)$ & $0.25 \mathrm{~m}$ \\
\hline
\end{tabular}

SN Applied Sciences 
Fig. 6 Verification of simulated model results against experimental data of wave-pile interaction by Zang et al. [3]
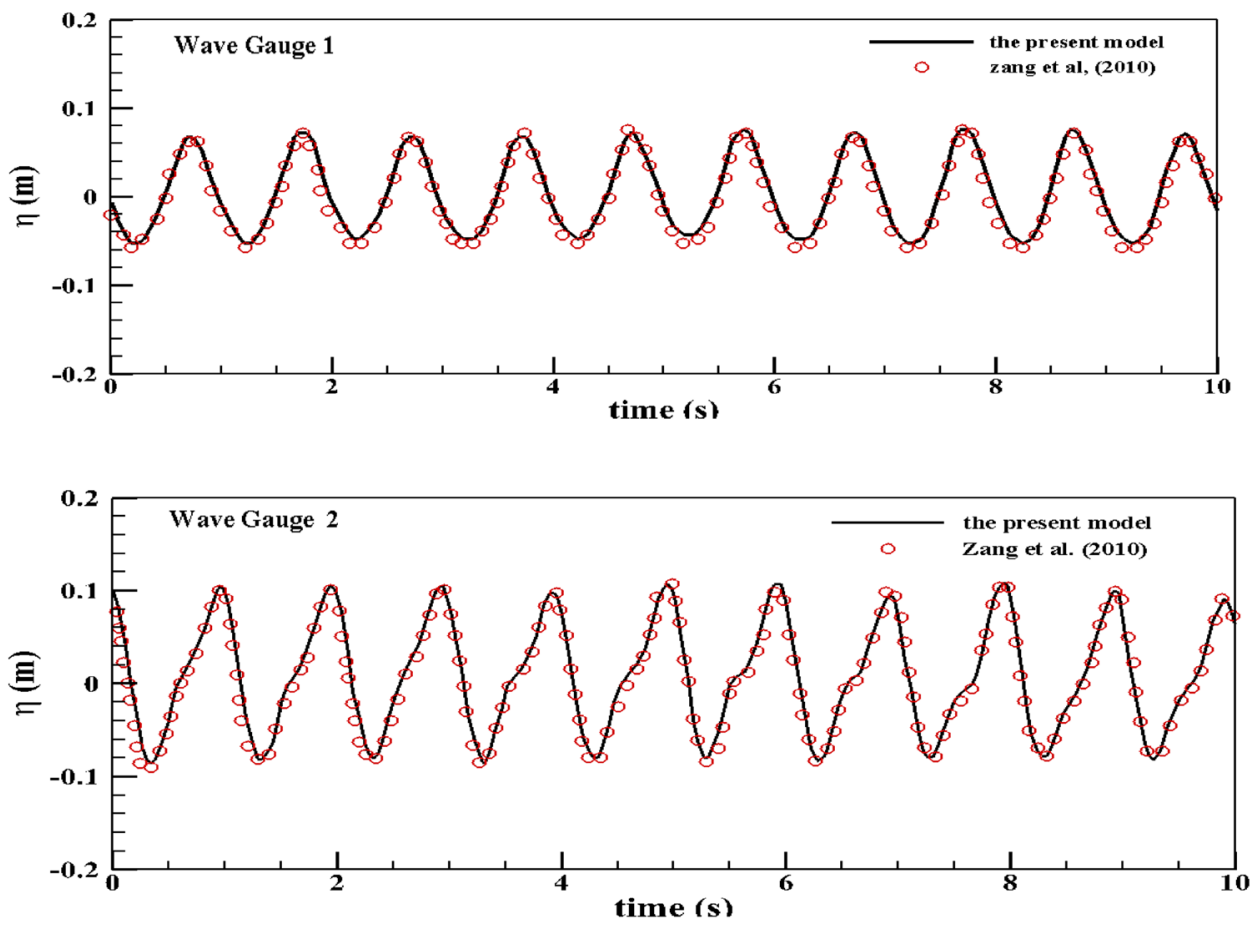

Figure 6 illustrates the verification between the simulated model and laboratory experiment results for the free surface elevation for wave gauge 1 and wave gauge 2. The results from the simulated model and the laboratory experiment depict a good agreement for the wave gauge 1 . However, for wave gauge 2 , the simulated and laboratory experimental results for the free surface elevation indicated a small sudden change at the upmost part. This change can be pointed to the close proximity of the wave gauge meter to the cylindrical pile structure. However, the overall comparison outcome shows that the present wave model has the capability to simulate wave-pile structure interaction.

\subsection{Comparison with Huang et al. (2017)'s physical experiment on the seabed}

Huang et al. [40] conducted a series of physical experiment on the pile-soil dynamic response within a waveflume on a fine porous sand seabed at Hohai University Laboratory Center of College of Coastal, Harbor and Offshore Engineering, China. The purpose of the experiment was to study the behavior of the dynamic response on the pile-soil interaction, the displacement of the projected top pile during wave action, the strain of the pile body during wave action and the changes in excess static pore water pressure within the seabed. Figure 7 depicts the layout
Fig. 7 Layout for wave flume experimental test

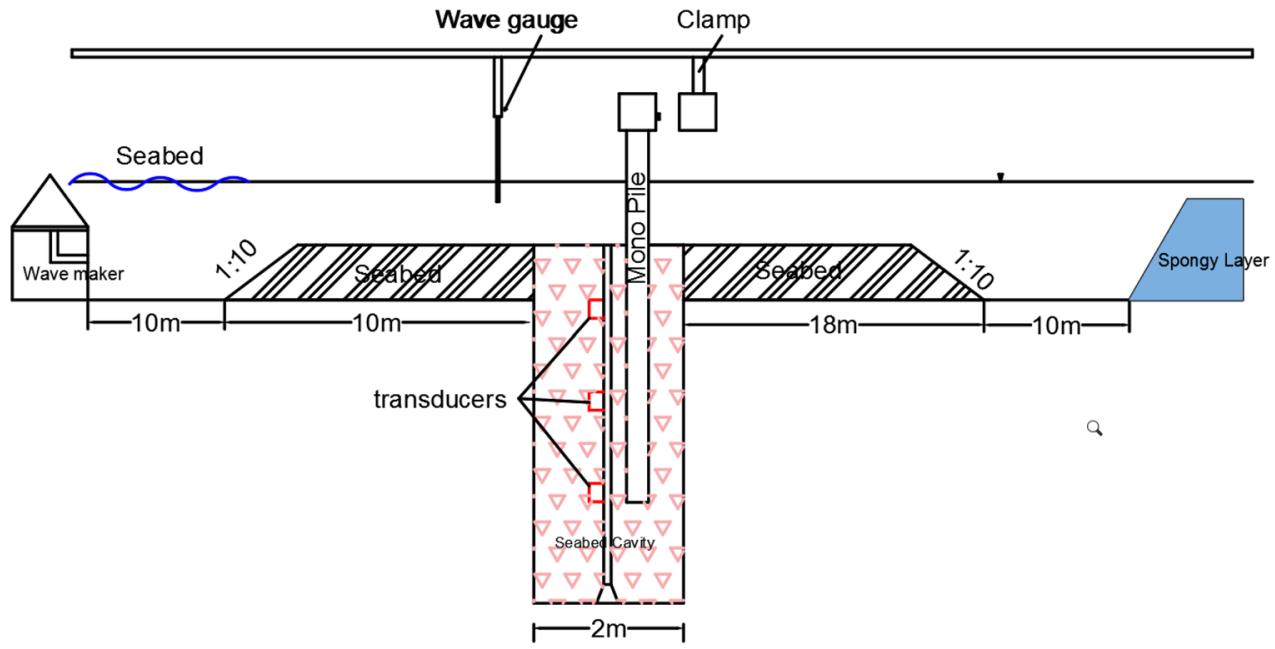


for the experiment within the wave-flume. The scale of the wave flume measurement applied in this physical model experiment is $50 \mathrm{~m}$ long $\times 1 \mathrm{~m}$ wide $\times 1.3 \mathrm{~m}$ high according to the suggested experiment from Tzang and Ou [41]. In order to ensure the depth of the pile, a grove of $35 \mathrm{~cm}$ thick and $2 \mathrm{~m}$ wide is arranged as shown in the figure. Table 4 indicates the physical parameters for the experiment. In the experiment, a glass tube with an elastic modulus of $3.19 \mathrm{Gpa}$ was used as the monopile structure.

Table 4 Input data parameter for the physical experiment on the wave-flume

\begin{tabular}{lll}
\hline Sub-model & Parameter & Value \\
\hline Pile parameter & Pile diameter $(D \varnothing)$ & $0.03 \mathrm{~m}$ \\
& Pile length $(L)$ & $1 \mathrm{~m}$ \\
& Pile burial depth $\left(D_{h}\right)$ & $0.3 \mathrm{~m}$ \\
Wave parameter & Wave height $(H)$ & $0.10 \mathrm{~m}$ \\
& Water depth $(d)$ & $0.3 \mathrm{~m}$ \\
Sand parameter & Wave period $(T)$ & $1 \mathrm{~s}$ \\
& Permeability $\left(K_{s}\right)$ & $1.8 \times 10^{-3} \mathrm{~m} / \mathrm{s}$ \\
& Porosity $\left(n_{s}\right)$ & 0.3 \\
& Particle size $\left(d_{50}\right)$ & $0.334 \mathrm{~m}$ \\
& Degree of saturation $\left(S_{r}\right)$ & 0.98 \\
\hline
\end{tabular}

Three pore water pressure transducers/sensors were mounted to record the excess pore water pressure in the sandy seabed. The pore pressure transducers were buried at three different depth (i.e. $Z=5 \mathrm{~cm}, 15 \mathrm{~cm}$, and $25 \mathrm{~cm}$ ) below the mud line.

Figure 8 shows the comparisons of the simulated model results with the physical laboratory results carried out within the wave flume. As illustrated in Fig. 8 , the highest excess pore water pressure recorded occurred at $Z=5 \mathrm{~cm}$ with a magnitude of $40 \mathrm{kPa}$. The reason being its closeness to the seabed surface. This also explained the reason why the oscillatory wave-induced response decreases with depth. Figure 8, shows the comparison of both model results depicting a good agreement between them.

\section{Results and discussion}

The purpose of this research is to investigate the interaction between the wave-porous seabed and three different pile support foundations. As shown in Fig. 5, the present numerical model is scaled to field conditions to investigate the responses of the porous seabed and the pile support piles under 3-dimensional wave loading action impact.
Fig. 8 Comparisons of simulated results against the wave-flume results for change in excess pore water pressure for the various depths
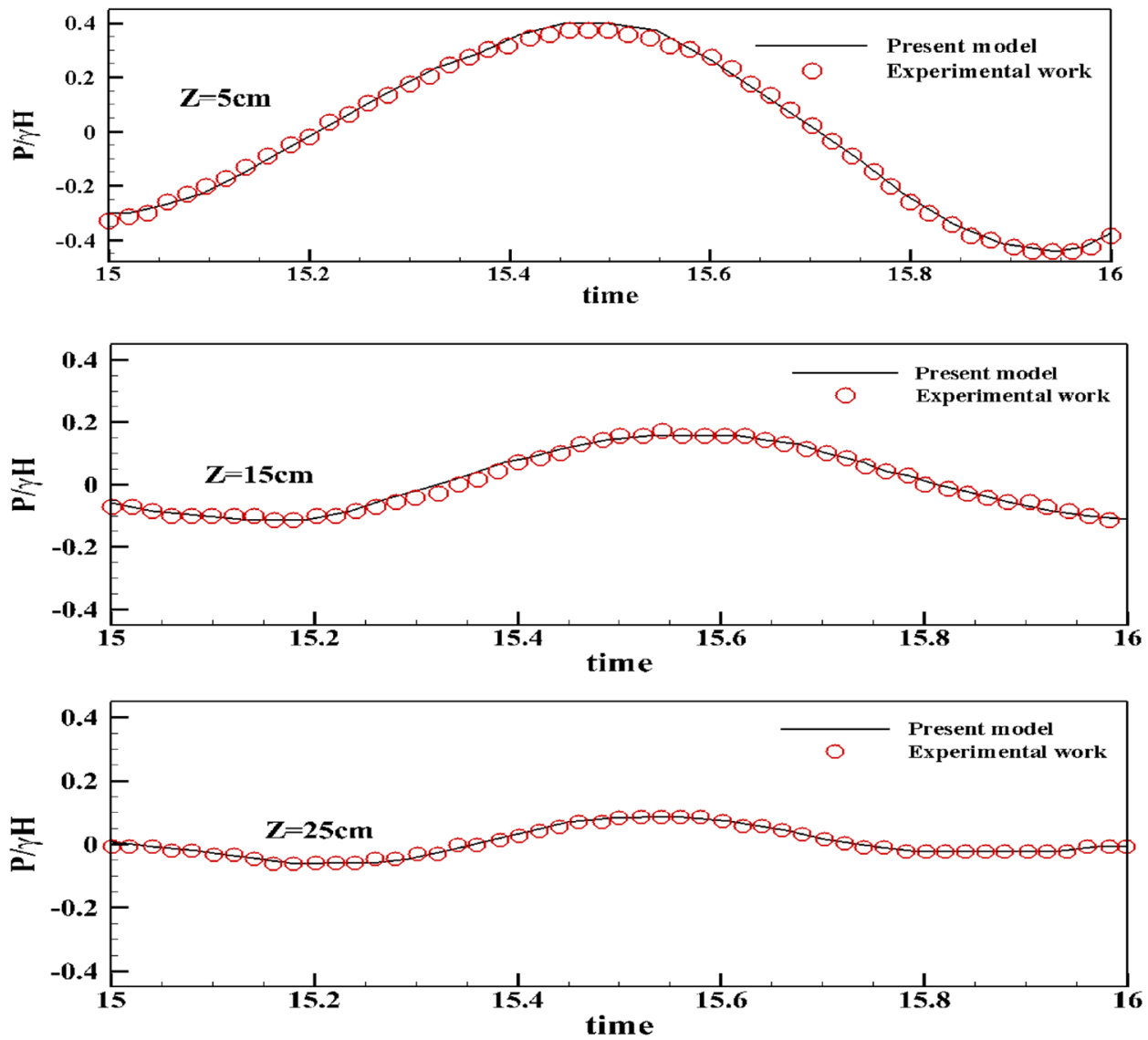

SN Applied Sciences 
In this section, studies are conducted to investigate the hydrodynamic process involve in the wave-structure foundation, which has been well identified to affect the propagating wave in the surrounding foundation [36, 42], wave pressure around the pile support structures, the wave force and its distribution on the pile structures. The parameter for the investigation study is tabulated in Table 5.

\subsection{Free surface elevation}

Figure 9 illustrates a comparative analysis between free surface elevation around the three configuration cases of the pile support foundations for three different locations, these are the upstream side (location A), the lateral edge (location B) and the downstream side (location C). It can be observed that the free surface elevation at these locations for the three different types of support piles foundation presented a noticeable difference. At the upstream side of the pile foundation (location A), the magnitude of the free surface elevation on the monopile support structure is seen to be relatively the same with the gravity-based and the tripod support pile structure. However, at location B and location $C$, the magnitude of the tripod support pile and the gravity-based pile is noticeably larger with higher peak value. The reason is due to the fact that, at location $A$, reflection from the pile is minimized by the additional legs of tripod support pile and coning based support for the gravity pile, which act as a blockage effect on the wave reflection. However, at location $B$ and location $C$, the additional legs of the tripod pile structure and base support of the gravity-based pile increase the peak variation of the

Table 5 Numerical model input parameter

\begin{tabular}{lll}
\hline Sub-model & Parameter & Value \\
\hline Pile characteristics & Pile diameter $(D \varnothing)$ & $1.4 \mathrm{~m}$ \\
& Pile length $\left(L_{p}\right)$ & $49 \mathrm{~m}$ \\
& Pile burial depth $\left(D_{h}\right)$ & $21 \mathrm{~m}$ \\
& Young's modulus $\left(E_{p}\right)$ & $7.9 \times 10^{11} \mathrm{~N} / \mathrm{m}^{2}$ \\
& Poisson's ratio $\left(\mu_{p}\right)$ & 0.25 \\
Wave characteristics & Wave height $(H)$ & $6.5 \mathrm{~m}$ \\
& Water depth $(d)$ & $24 \mathrm{~m}$ \\
Seabed characteristics & Wave period $(T)$ & $8 \mathrm{~s}$ \\
& Permeability $\left(K_{s}\right)$ & $1.0 \times 10^{-3} \mathrm{~m} / \mathrm{s}$ \\
& Porosity $\left(n_{s}\right)$ & 0.44 \\
& Degree of Saturation $\left(S_{r}\right)$ & 0.98 \\
& Young's modulus $\left(E_{s}\right)$ & $2.0 \times 10^{7} \mathrm{~N} / \mathrm{m}^{2}$ \\
& Poisson's ratio $\left(\mu_{s}\right)$ & 0.33 \\
& Seabed thickness $(h)$ & $40 \mathrm{~m}$ \\
& Seabed width $(B)$ & $40 \mathrm{~m}$ \\
& Seabed length $(L)$ & $200 \mathrm{~m}$ \\
\hline
\end{tabular}

SN Applied Sciences

A SPRINGER NATURE journal wave propagation. The highest magnitude observed for all the pile support foundation structures is noticed at the upstream side, that is in front of the pile surface, whereas the smaller wave magnitude is observed at the lee-side at location $C$ due to the strong effect of the blockage from the pile structures at that location. It can be therefore summarized that free surface elevation around the three types of pile support structures differs from each other due to their orientation.

\subsection{Wave pressure}

Figure 10 demonstrates the comparative time series of wave pressure in the environs of the three different types of the pile support structures at upstream (location A), lateral (Location B) as well as the downstream (location C). It is noticed that during propagation the amplitude of wave pressure towards the pile support foundation at location $\mathrm{A}$, is moderate and almost the same. Bedside, the magnitude of wave pressure at the upstream (i.e. location A) for the three different cases of the pile support foundation is higher than the downstream (location C). This indication shows the reason why wave energy dissipates during wave propagation as a result of fluid- pile structure interaction, also the pile support foundation significantly influences the wave motion. It is also shown that at the lateral side (location B) and the lee-side (location C) of the seabed foundation, the gravity-based, and the tripod support pile is observed to have the highest wave pressure amplitude and largest magnitude. The fact of the matter is that the additional support legs of the tripod support pile and the coning base foundation of gravity-based pile greatly induced the wave pressure thereby compelling it to generate higher wave pressure than that of the monopile.

\subsection{Wave force}

In the process of investigating the WSSI problem, it is important to accurately model the wave force on the structure and subsequently on the seabed. Figure 11 illustrates the comparison between the time history series curve of the longitudinal wave load impacting on the three configuration cases of pile support structures. The outcome of maximum wave load from the results occurred at the gravity-based support structure followed by the tripod and the monopile support structure. The main reason for this is attributable to the large surface occupied by the gravity-based pile as compared to the other pile support structures.

Figure 12 shows the vertical distribution of the dynamic wave force acting on the three configuration cases of pile support structures at the upstream side (location A). An investigation has established that the magnitude of the 
Fig. 9 Comparison of time series of free surface elevation for different types of pile structures at three typical locations
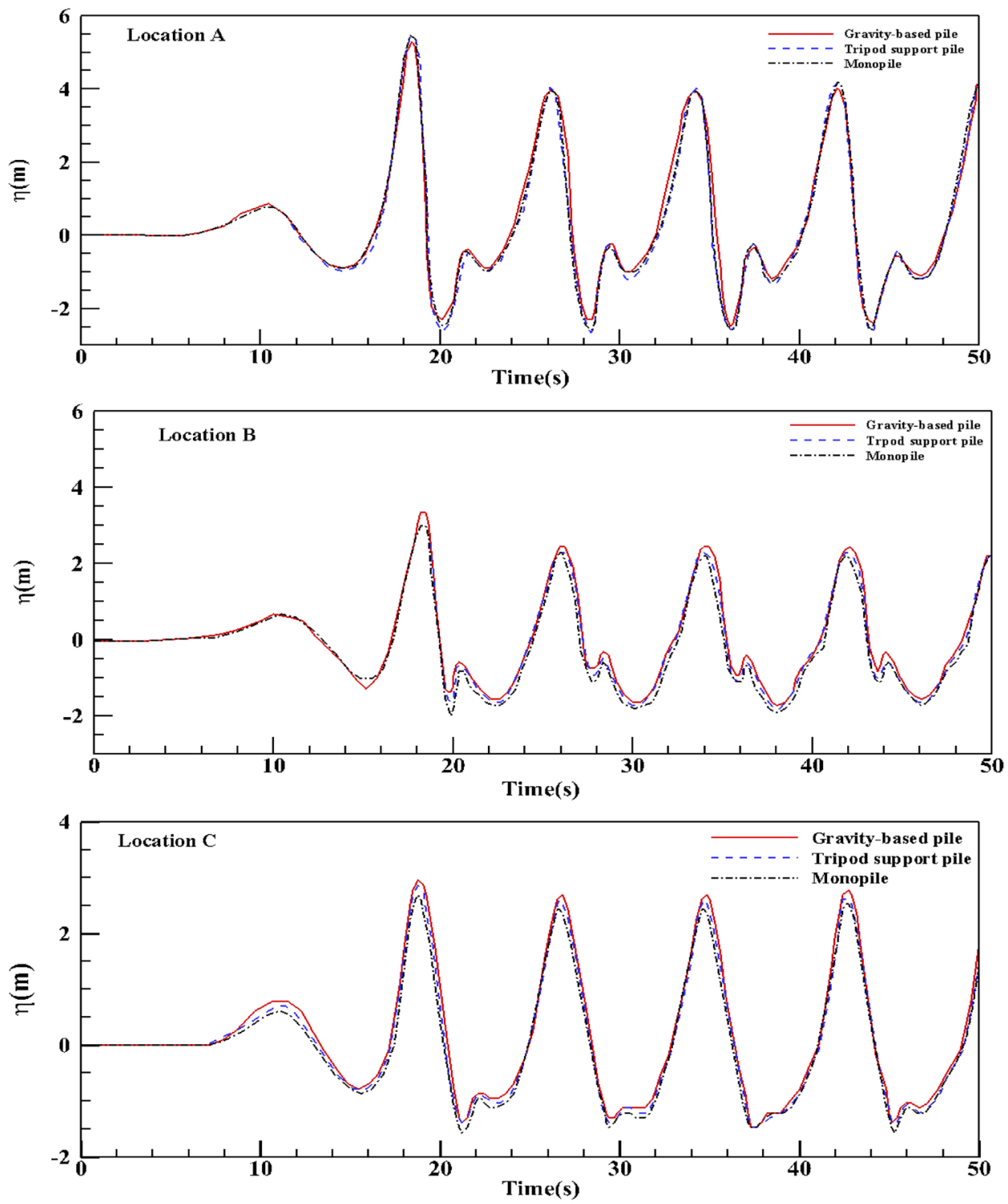

wave impact force is correlated with the wave run-up and run-down of the wave on the pile support structures. The maximum free surface run-up and run-down happens when the maximum wave crest and wave trough slap against the piles support structures surface at $t=31 \mathrm{~s}$ and $t=34 \mathrm{~s}$ respectively where a most significant force impact on the pile surface is generated. The wave force distribution diagram in Fig. 12 can also be comparatively observed that the wave impact force on the gravity-based pile is higher than the tripod and monopile support structures.

\subsection{Dynamic pore pressure and liquefaction around the support pile structures}

In the WSSI study, wave-induced pore pressure in seabed foundation plays a major concern to coastal engineers and geotechnical researchers. Many research has carried out an investigation on it to examine offshore structures such as breakwater [26, 32, 43-45], submarine pipe structures [46-48] as well as pile structures [19, 21, 49]. In principle, excessive pore pressure in the poro-seabed foundation has the tendency to diminish the effective stresses in the solid seabed soil and further induced to liquefaction, which may affect the support of the offshore structure. In this section, the oscillatory waveinduced pore pressure and seabed liquefaction depth around the three configuration cases of the pile support foundations will be analyzed. In this present study, the three different types of pile structures are assumed to be rigid impenetrable bodies and the influence of vibration on the solid seabed foundation is not considered. Readers can refer to Fattah et al. [50] for further studies on pile vibration. 
Fig. 10 Comparison of time series of wave pressure on the seabed surface for different types of pile structures at three typical locations
Fig. 11 Comparisons of wave impact forces exerted on the three different types of pile support structures
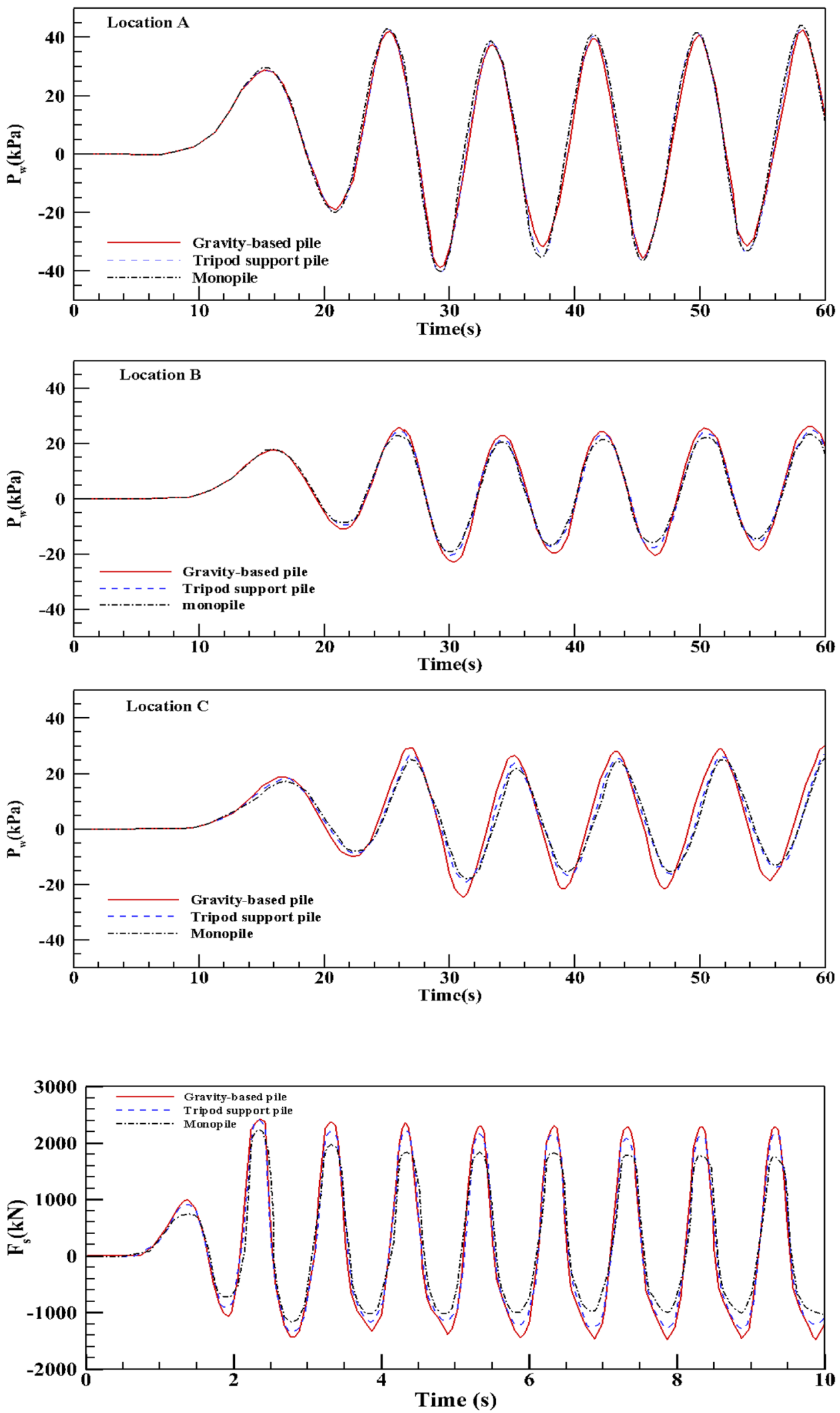
Fig. 12 Distribution of waveimpact force on the three configuration cases of pile structures at different periods. Note black line for gravitybased pile, dash blue for a tripod pile, and dash-dot red line for monopile
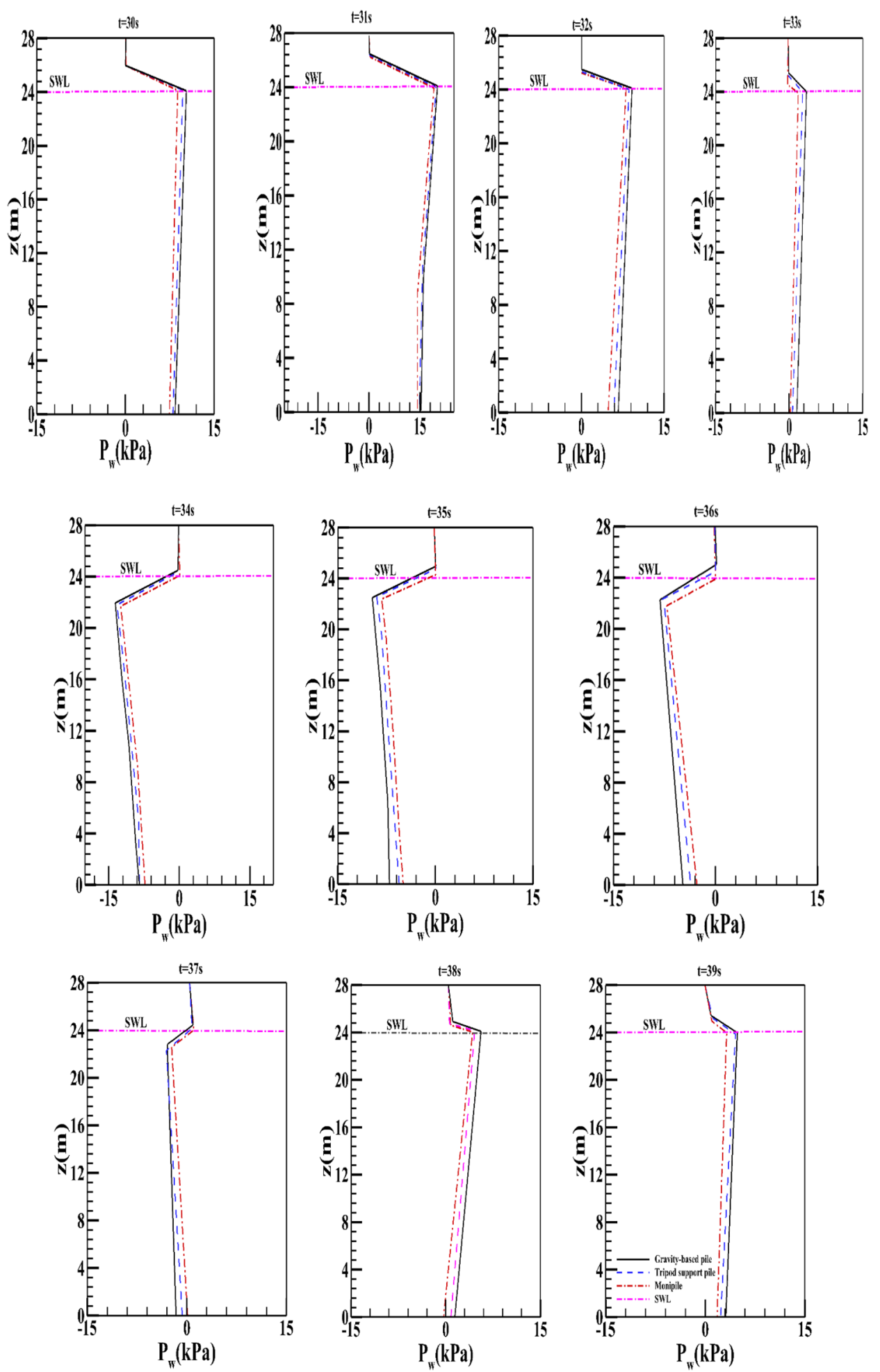

\subsubsection{Wave-induced pore pressure}

Figures 13 and 14 demonstrate the distribution of oscillatory wave-induced pore pressure $\left(p_{s}\right)$ around three different types of pile support structures on the xyz plane at a two typical time interval $t=31 \mathrm{~s}$ when the wave crest just slaps against the top part of the pile structure and $t=34 \mathrm{~s}$, when the wave trough slaps against the top part of the pile structure. The figure clearly depicts that the magnitude of wave-induced pore pressure attenuates dramatically near the seabed depth and almost equal to zero in soil depth. It can be observed that the pore pressure $\left(p_{s}\right)$ 
Fig. 13 Snapshot of waveinduced pore pressure distribution around a Monopile $\mathbf{b}$ tripod pile and c gravity-based pile at $\mathrm{t}=31 \mathrm{~s}$, when the wave crest collapses into the pile structure
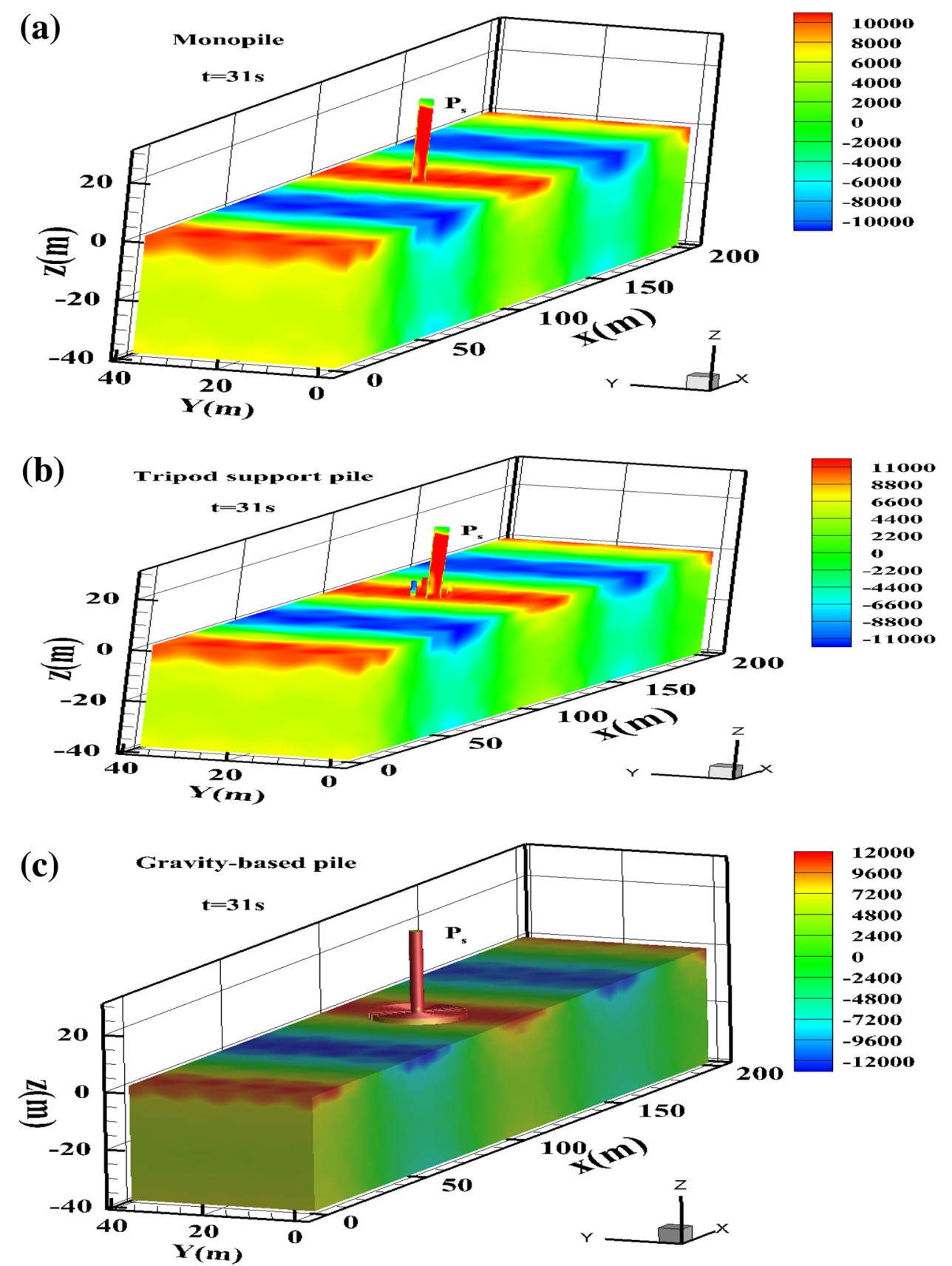

in the seabed in the xyz plane is significantly induced in front of the pile structure within a seabed depth of $40 \mathrm{~m}$, indicating that the seabed in front of the pile structures requires adequate attention in engineering practices due to its proneness to liquefaction. As shown from the figure, when the wave crest slaps against the head of the pile structure the oscillatory wave-induced pore pressure on the plane increased with an amplitude of $100 \mathrm{kPa}, 110 \mathrm{kPa}$, and $120 \mathrm{kPa}$ for the monopile, tripod support, and the gravity-based support pile respectively.

To dealt insight into the momentary wave-induced pore pressure around the pile structures Fig. 15 is employed to show the vertical pore pressure distribution at locations $A$, $B$, and $C$. These three locations are close and around the pile structures. In this subsection, comparatively analysis on vertical distribution pore pressure on seabed response at a various location for the configuration of the three different types of pile support structures is examined.

As illustrated in Fig. 15 the amplitude variation of pore pressure considerably decreases against the seabed depth when $|z|<2.4 \mathrm{~m}$ for all three locations and remained constant in the soil depth. This indicates that the wave impact on seabed response is deeply concentrated in the scope of the shallow seabed surface. As shown from Fig. 14, the 
Fig. 14 Snapshot of waveinduced pore pressure distribution around a monopile $\mathbf{b}$ tripod pile and c gravity-based pile at $\mathrm{t}=34 \mathrm{~s}$, when the wave trough collapses into the pile structure
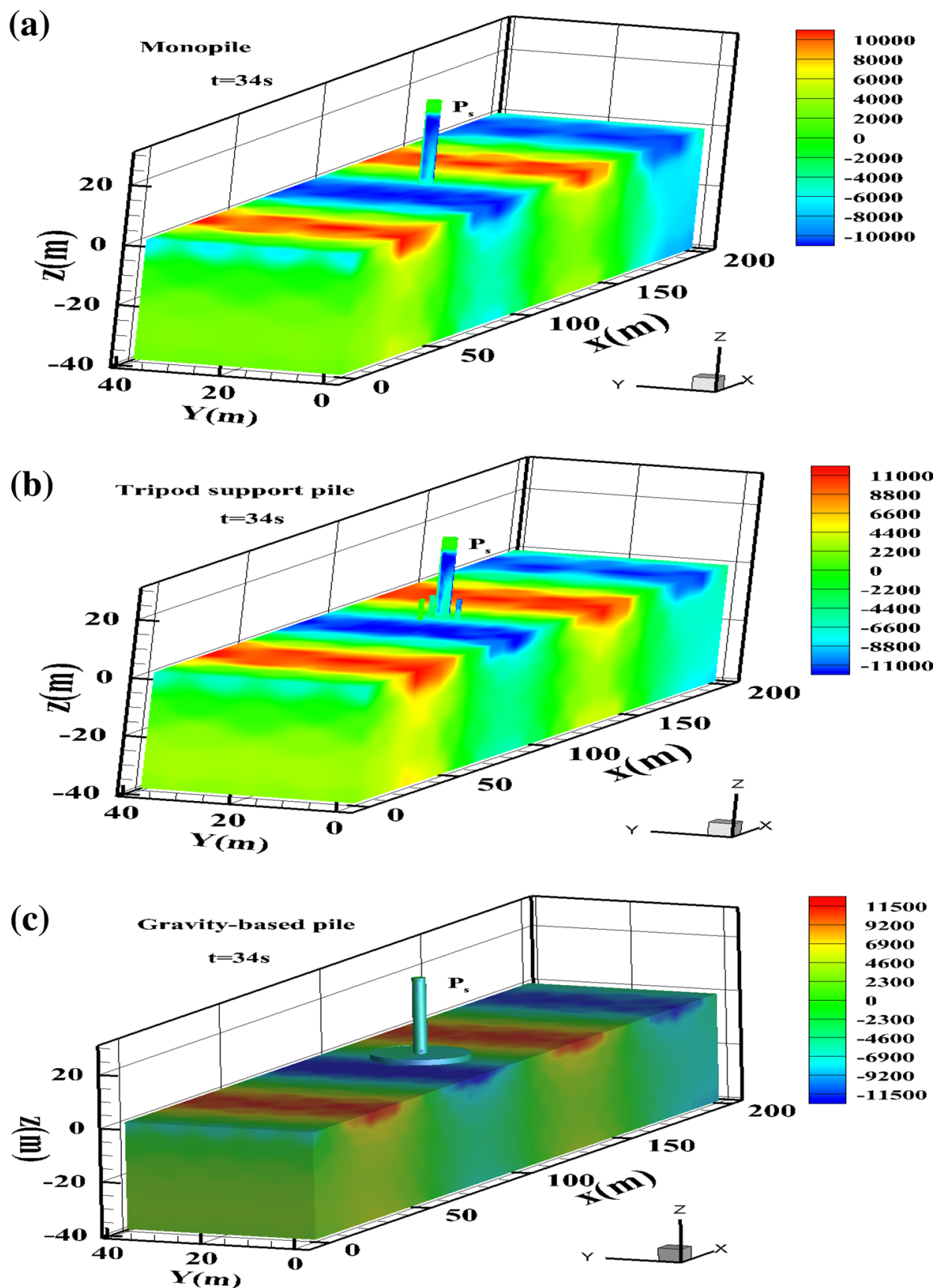

pore pressure in location $A, B$ and $C$ reaches their maximum when $t / T=6.2$. When the pore pressure at location $A$, reaches its maximum pore pressure at $t / T=6.2$, the comparison between these three configuration cases of pile support piles shows that the magnitude of the pore pressure distribution profile indicates almost the same variation. This may perhaps be due to reflection from the piles. At locations, $B$ and $C$ the maximum pore pressure distribution for the three configuration cases of pile support piles shows that the magnitude variation of pore pressure from the gravity-based support pile and tripod support pile is significantly larger than that of the monopile. This is due to the blocking effect exhibited from both the gravity-based foundation and the additional legs from the tripod pile.

\subsubsection{Wave-induced seabed liquefaction}

The increase of excess pore pressure underneath the wave propagation decreases the effective stresses in the seabed foundation which leads to seabed liquefaction around the pile structure and its consequent effect result in erected pile structure collapsing. Wave-induced 
Fig. 15 Comparison of waveinduced pore pressure for three configuration cases of pile support piles at various locations
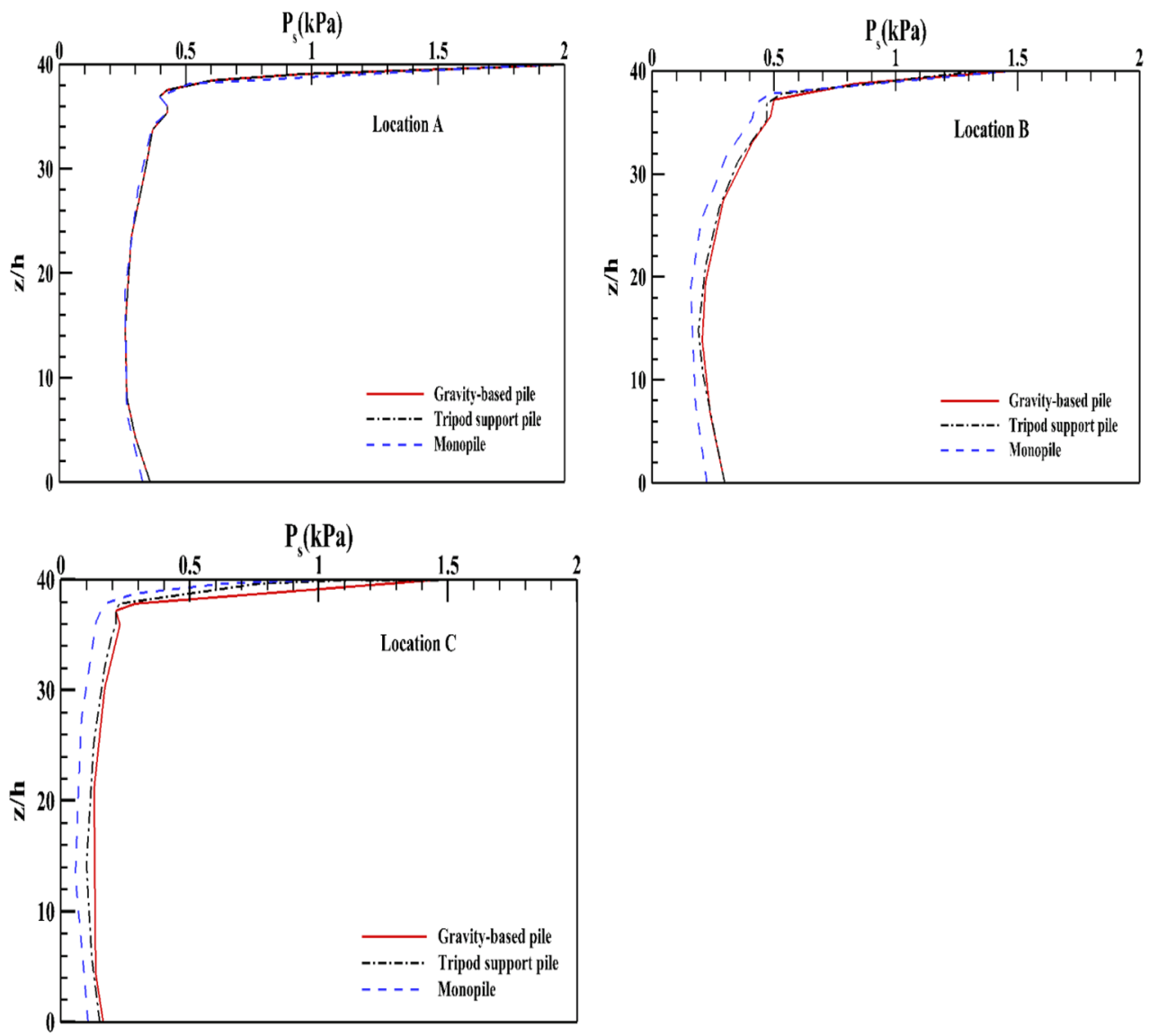

liquefaction is a great concern in offshore engineering practices. Accurate forecast of liquefaction zones in the surrounding of pile foundation can help engineers revise design plans and enhance the reliability of the structure. In this study, the proposed criteria work of Jeng $[36,51]$ is applied to characterize the wave-induced liquefaction zones around the three different types of pile foundations, which is expressed as:

$$
-\frac{1}{3}\left(\gamma_{s}-\gamma_{w}\right)\left(1+2 k_{o}\right) z+\frac{1}{3}\left(\sigma_{x}^{\prime}+\sigma_{y}^{\prime}+\sigma_{z}^{\prime}\right) \leq p_{s}-p_{b}
$$

where $k_{o}=$ [coefficient of lateral earth pressure at rest], $\gamma_{s}=$ [the unit weight of sand particles]; $\gamma_{w}=$ [the unit weight of water]; $p_{s}=$ [wave-induced pore pressure with the seabed]; $p_{b}=$ [dynamic wave pressure]; $\sigma_{x}^{\prime}, \sigma_{y^{\prime}}^{\prime}$ $\sigma_{\mathrm{z}}^{\prime}=$ [mean effective stresses induced by waves on seabed in the xyz-direction].

Equation (27) simply means that seabed liquefaction can happen when the overburden soil pressure is less than excess pore pressure. The solid soil only reaches a liquefied status only when at any given depth the seabed foundation value becomes zero or negative. In this section, a comparison of wave-induced liquefaction potential will be carried out to estimate the liquefied

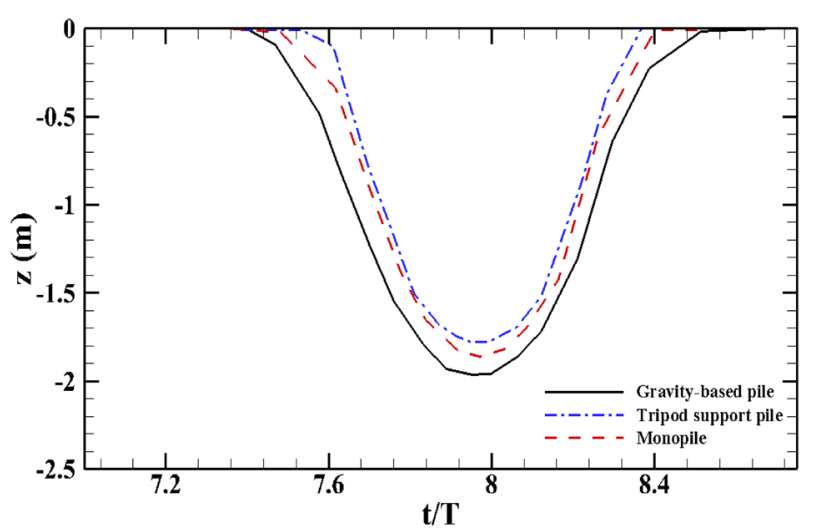

Fig. 16 Potential liquefaction depth at front side of the three configuration cases of pile structures

depth for three configuration cases of pile foundations in agreement with the wave and seabed parameter tabulated in Table 5.

Figure 16 illustrates a comparison of the wave-induced liquefaction depth variation at the upstream side of the seabed for the three configuration cases of the pile structures when $t / T=6.8$. It is clearly observed that the maximum wave-induced liquefaction of $z=2.2 \mathrm{~m}$ within the 
Fig. 17 Contour profile for liquefaction depth in the vicinity of monopile and gravity-based pile at $\mathrm{t} / \mathrm{T}=6.8$
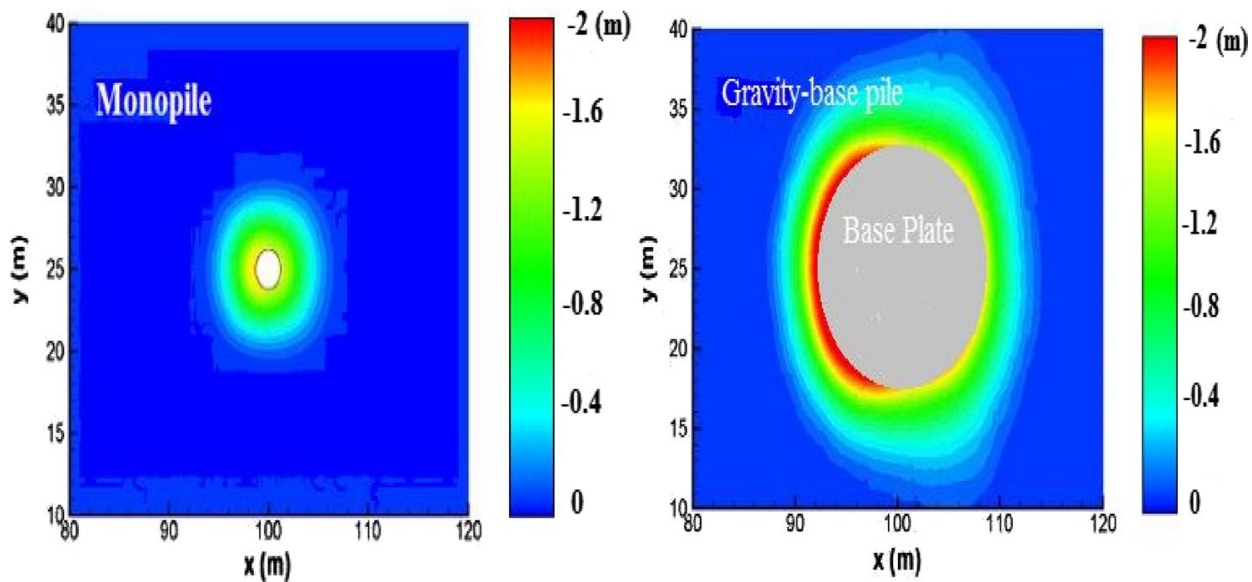

seabed surface foundation occurred around the large diameter coning base of the gravity-based foundation. As one can see from the figure, the tripod support pile appeared to have the minimum potential liquefaction depth of $1.7 \mathrm{~m}$, which may perhaps be due to additional legs joined up to the main pile.

Figure 17 illustrates a snapshot of the contour profile of liquefaction depth around the monopile and gravitybased support pile at $\mathrm{t} / \mathrm{T}=6.8$ when wave trough slaps with these piles. The liquefaction depth around the pile is uniform in the $x-y$ direction. The liquefaction range in the $x$-axis and $y$-axis are $80 \mathrm{~m}$ to $120 \mathrm{~m}$ and $10 \mathrm{~m}$ to $40 \mathrm{~m}$ respectively. As shown from the illustrated figure the potential liquefaction around both the monopile and gravity-based support pile are with different varying diameter base from $D \varnothing=2.8 \mathrm{~m}$ and $D \varnothing=20 \mathrm{~m}$ respectively. From the observation increasing the pile base diameter influence the wave force acting on the surface and hence result in wave-induced liquefaction. As seen from the figure the most sensitive location to wave-induced liquefaction appeared upstream (i.e. location A) of the pile structure. This is due to the increased pore pressure build-up at that location.

\section{Conclusions}

This study proposed a comparatively numerical analysis scheme to explore WSSI around three configuration cases of wind turbine foundations. The oscillatory wave-induced pore pressure around these three configuration cases of piles foundation is explored and discussed in detail. The main conclusions for this study can be drawn as follows:

1. The verification of the present study shows that the present model has the capability and capacity to simulate WSSI around the different types of pile support structures. The simulated numerical time series dia- gram of free surface elevation for the three configuration cases of pile structures agreed well with experimental results.

2. Hydrodynamic comparison analysis such as wave pressure, free surface elevation and wave force on the seabed resulting from the three different cases of the pile support structures shows the gravity-based support pile tend to generate higher magnitude free surface elevation and wave pressure as well as the wave force effect on it is higher due to perhaps the large surface area it occupied.

3. The oscillatory wave-induced pore pressure comparison analysis in the seabed foundation around the three different types of pile support structures shows that the wave-induced pore for the gravity-based support pile and the tripod support pile at the lateral side and the downstream side of the seabed foundation are significantly higher than that of the monopile structure.

4. Liquefaction depth analysis for three configuration cases of pile structures at the upstream side within the seabed foundation shows that the tripod support pile has higher tendency resistance against wave-induced liquefaction, which may be due to the additional legs whereas the gravity support pile tends to be greatly affected by the wave-induced liquefaction due to the large coning base diameter.

Acknowledgement This research paper is jointly supported by the National Natural Science Foundation of China (51920105013), the national key research and development program of China (2017YFC1404200) and the Hydrological Services Department, under the Ministry of Works and Housing, Ghana. Thanks also go to Amandi Holdings in Ghana for their support.

Author contributions RA formulated the idea and wrote the manuscript while JZ supervised and reviewed the manuscript. HZ, HOW and $A B A$ reviewed the manuscript. 


\section{Compliance with ethical standards}

Conflict of interest On behalf of all authors, the corresponding author states that there is no conflict of interest.

\section{References}

1. Intergovernmental Panel on Climate Change (IPCC) Climate Change 2014 Synthesis Report-IPCC; 2014; ISBN 9789291691432

2. IPCC (2011) IPCC Special report on renewable energy sources and climate change mitigation. Cambridge University Press, Cambridge, United Kingdom

3. Zang J, Taylor PH, Tello M (2010) Steep wave and breaking wave impact on Offshore wind turbine foundations-ringing re-visited. International workshop on water waves and floating bodies (IWWWFB25). Harbin, China, pp 9-12

4. Houlsby $G$ (2016) Interactions in offshore foundation design. Géotechnique 66(10):791-825

5. Christian JT, Taylor PK, Yen JKC, Erali DR (1974) Large diameter underwater pipe line for nuclear power plant designed against soil liquefaction. In: Proceedings of the offshore technology conference

6. Smith AWS, Gordon AD (1983) Large breakwater toe failures. J Waterw Port Coast Ocean Eng 109:253-255

7. Lundgren H, Lindhardt JHC, Romhild CJ (1989) Stability of breakwaters on porous foundation. In: Proceedings of the 12th international conference on soil mechanics and foundation engineering, vol 1, pp 451-454

8. Sterling GH, Strohbeck GE (1973) The failure of the South Pass 70 Platform B in Hurricane Camille. Proc Offshore Technol Conf 5:720-724

9. Wright SG (1976) Analyses for wave induced sea-floor movements. In: Proceedings of the offshore technology conference; offshore technology conference

10. Miceli F, Offshore wind turbines foundation types. http://www. windfarmbop.com/offshore-windturbines-foundation-types/

11. Stuyts B, Cathie D, Xie Y (2013) Scour assessment and measurements for pile-supported wind turbine foundations. In: ASME 2013 32nd International Conference on Ocean, Offshore and Arctic Engineering, pp V006T10A025-V006T10A025

12. Yuan C, Melville BW, Adams KN (2017) Scour at wind turbine tripod foundation under steady flow. Ocean Eng 141:277-282

13. Zhang Q, Zhou XL, Wang JH (2017) Numerical investigation of local scour around three adjacent piles with different arrangements under current. Ocean Eng 142:625-638

14. Lin YH, Chen JF, Lu PY (2017) A CFD model for simulating wave run-ups and wave loads in case of different wind turbine foundations influenced by nonlinear waves. Ocean Eng 129:428-440

15. Li XJ, Gao FP, Yang B, Zang J (2011) Wave-induced pore pressure responses and soil liquefaction around pile foundation. Int J Offshore Polar Eng 21(3):233-239

16. Chang KT, Jeng DS (2014) Numerical study for wave-induced seabed response around offshore wind turbine foundation in Donghai offshore wind farm, Shanghai, China. Ocean Eng 85:32-43

17. Zhang C, Zhang Q, Wu Z, Zhang J, Sui T, Wen Y (2015) Numerical study on effects of the embedded monopile foundation on local wave-induced porous seabed response. Math Probl Eng 3:1-13

18. Zhang C, Sui T, Zheng J, Xie M, Nguyen VT (2016) Modelling wave-induced 3D non-homogeneous seabed response. Appl Ocean Res 61:101-114
19. Sui T, Zhang C, Guo Y, Zheng J, Jeng D, Zhang J, Zhang W (2016) Three-dimensional numerical model for wave-induced seabed response around mono-pile. Ships Offshore Struct 11:667-678

20. Lin Z, Pokrajac D, Guo Y, Jeng D-S, Tang T, Rey N, Zheng J, Zhang J-S (2017) Investigation of nonlinear wave-induced seabed response around mono-pile foundation. Coast Eng 121:197-211

21. Zhao HY, Jeng D, Liao CC, Zhu JF (2017) Three-dimensional modeling of wave-induced residual seabed response around a mono-pile foundation. Coast Eng 128:1-21

22. LiY, Ong MC, Tang T (2018) Numerical analysis of wave-induced poro-elastic seabed response around a hexagonal gravity-based offshore foundation. Coast Eng 136:81-95

23. Hanssen AG, Tørum A (2002) Breaking wave forces on tripod concrete structure on shoal. J Waterway Port Coast Ocean Eng 125(6):304-310

24. Hildebrandt A, Sriram V, Schlurmann T (2013) Simulation of focusing waves and local line forces due to wave impacts on a tripod structure. In: Proceedings of the twenty-third international offshore and polar engineering

25. Mo R, Li M, Kang H (2016) Wave interaction with a tripile foundation using SBFEM. In: Proceedings of the twelfth ISOPE Pacific/ Asia offshore mechanics symposium; International Society of Offshore and Polar Engineers

26. Ye J, Jeng D, Wang R, Zhu C (2013) A 3-D semi-coupled numerical model for fluid-structures-seabed-interaction (FSSI-CAS 3D): model and verification. J Fluids Struct 40:148-162

27. Sassa S, Sekiguchi H, Miyamoto J (2001) Analysis of progressive liquefaction as a moving-boundary problem. Géotechnique $51: 847-857$

28. COMSOL Multiphysics COMSOL Multiphysics. 3rd edition 2010

29. Zhao HY, Jeng DS, Liao CC (2016) Parametric study of the waveinduced residual liquefaction around an embedded pipeline. Appl Ocean Res 55:163-180

30. Lin Z, Guo Y, Jeng D, Liao C, Rey N (2016) An integrated numerical model for wave-soil-pipeline interactions. Coast Eng 108:25-35

31. Zhao H, Jeng D (2015) Numerical study of wave-induced soil response in a sloping seabed in the vicinity of a breakwater. Phys Procedia 51:204-221

32. Liao C, Tong D, Chen $L$ (2018) Pore pressure distribution and momentary liquefaction in vicinity of impermeable slope-type breakwater head. Appl Ocean Res 78:290-306

33. Hsu T-J, Sakakiyama T, Liu PL-F (2002) A numerical model for wave motions and turbulence flows in front of a composite breakwater. Coast Eng 46:25-50

34. Rodi W (1980) Turbulent models and their application in hydraulics: a state of the art review. International Association for Hydraulic Research, Delft

35. Biot MA (1941) General theory of three dimensional consolidation. J Appl Phys 12:155-164

36. Jeng DS (2013) Porous models for wave-seabed interactions. Shanghai Jiao Tong University Press and Springer, Berlin, Heidelberg, 2013; vol 9783642335; ISBN 9783642335938

37. Yamamoto T, Koning HL, Sellmeijer H, Van Hijum EP (1978) On the response of a poro-elastic bed to water waves. J Fluid Mech 87:193-206

38. Larsen J, Dancy H (1983) Open boundaries in short wave simulations: a new approach. Coast Eng 7(3):285-297

39. Sui T, Zhang J, Zheng J, Zhang C (2013) Modeling of waveinduced seabed response and liquefaction potential around pile foundation. In: Proceedings of the ASME 2013 32nd international conference on Ocean, Offshore and Arctic Engineering; American Society of Mechanical Engineers, pp V006T10A013-V006T10A013 
40. Huang T, Zheng JH, Zhang JS, Yuan Y, Wu B (2017) Experimental study on the cyclic behavior of monopiles in fine sandy beds under regular waves. China Ocean Eng 31:607-617

41. Tzang SY, Ou SH (2006) Laboratory flume studies on monochromatic wave-fine sandy bed interactions: Part 1. Soil fluidization. Coast Eng 53:965-982

42. Sumer BM, Truelsen C, Fredsøe J (2006) Liquefaction around pipelines under waves. J Waterway Port Coast Ocean Eng 132(4):266-275

43. Jeng DS, Ye JH (2012) Three-dimensional consolidation of a porous unsaturated seabed under rubble mound breakwater. Ocean Eng 53:48-59

44. Asumadu R, Zhang J, Hubert O, Akoto AB (2019) Two-dimensional model of wave-induced response of seabed around permeable submerged breakwater. Adv Mech Eng 11:1-15

45. Zhang J, Jeng D, Liu PL, Zhang C, Zhang Y (2012) Response of a porous seabed to water waves over permeable submerged breakwaters with Bragg reflection. Ocean Eng 43:1-12

46. Zhou XL, Jeng DS, Yan YG, Wang JH (2013) Wave-induced multilayered seabed response around a buried pipeline. Ocean Eng 72:195-208
47. Zhai Y, He R, Zhao J, Zhang J, Jeng DS, Li L (2018) Physical model of wave-induced seabed response around trenched pipeline in sandy seabed. Appl Ocean Res 75:37-52

48. Liang Z, Jeng D-S (2019) A three-dimensional model for the seabed response induced by waves in conjunction with currents in the vicinity of an offshore pipeline using OpenFOAM. Int J Ocean Coast Eng 01:1850004

49. Tong D, Liao C, Jeng DS, Wang J (2018) Numerical study of pile group effect on wave-induced seabed response. Appl Ocean Res 76:148-158

50. Fattah MY, Mustafa FS (2017) Development of excess pore water pressure around piles excited by pure vertical vibration. Int J Civ Eng 15(6):907-920

51. Jeng DS (1996) Wave-induced seabed instability in front of a breakwater. Ocean Eng 24:887-917

Publisher's Note Springer Nature remains neutral with regard to jurisdictional claims in published maps and institutional affiliations. 